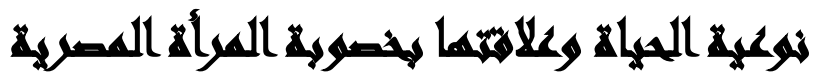

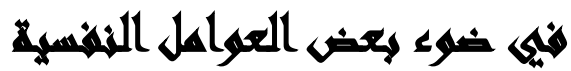

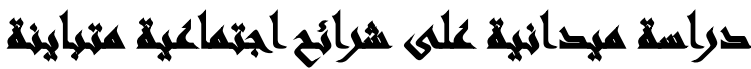

\section{[0]}

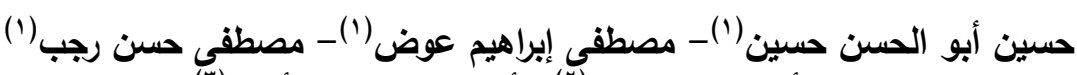

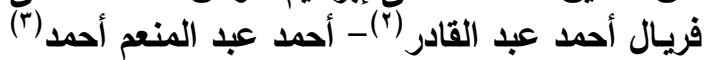

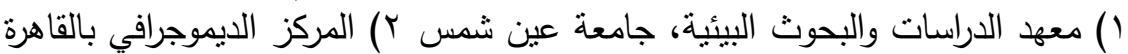
r) مدير المشروع العربي لصحة الأسرة، جامعة الدول العربية

\section{المستخليك}

تهدف هذه الدراسة إلى تحديد العلاقة بين خصوبة المرأة وبعض المتغيرات الدالة عليها

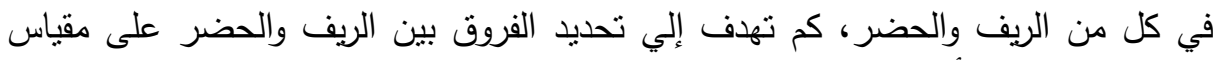

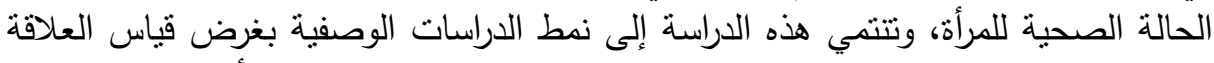

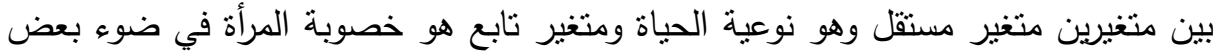

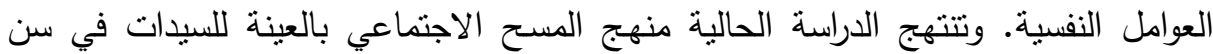

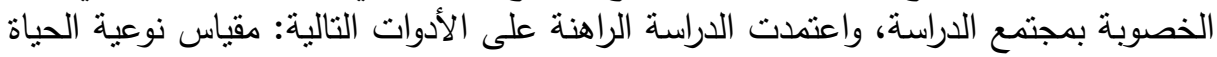
من إعداد الباحث، مقياس العوامل النفسية المؤثرة في خصوبة المئة المرأة من إعداد البادية الباحث.

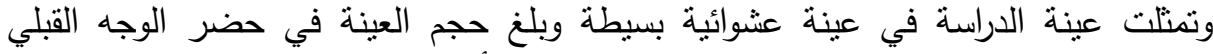

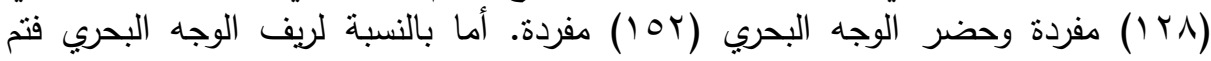

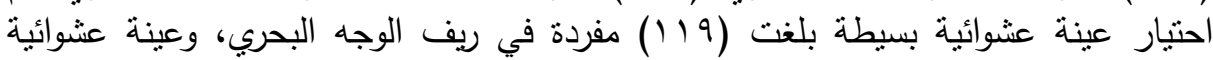

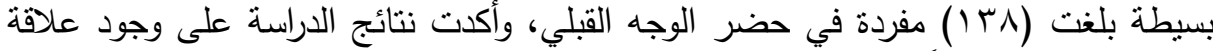

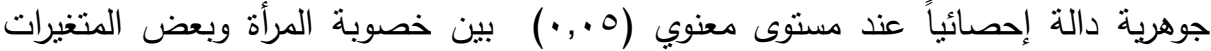

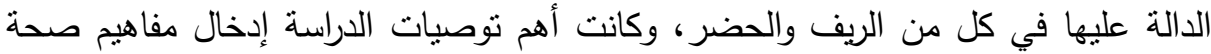
المرأة بشكل أساسي في مقررات التعليم من حيث تأثنيرات البيئة السلبية على سلى سلوك الإنية الإنسان عموماً، والمرأة على وجه الخصوص. 


\section{$\operatorname{xan}$}

تعتبر الخصوبة من العناصر الرئيسة للنمو السكاني وتؤثر في التركيب العمري للسكان،

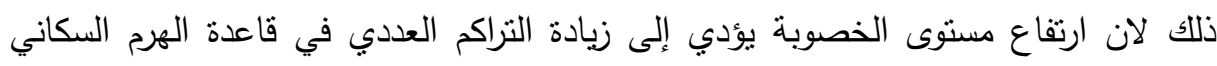

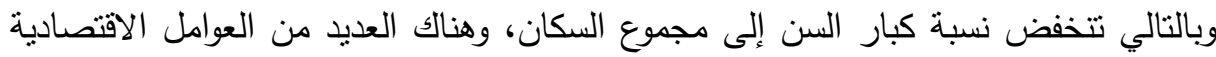
والاجتماعية والديموغرافية التي تؤثر على الخصوبة، بطرق مباشرة وغير مباشرة، ومن العوامل المباشرة التي تؤثر على الخصوبة، العمر عند الزواج، وسن البلوغ والرضاعة، وعديه وعدد الأطفال

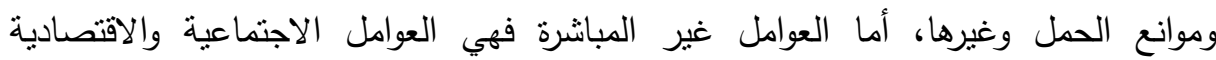

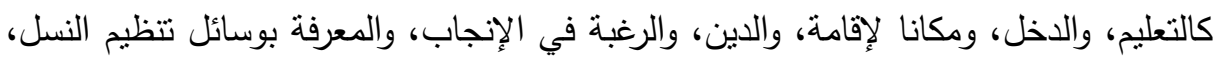

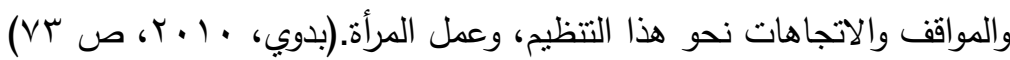
لقد شه عدد سكان مصر تزايدا خلا العقود الماضية فقد تضاعف عدد سكان مصر

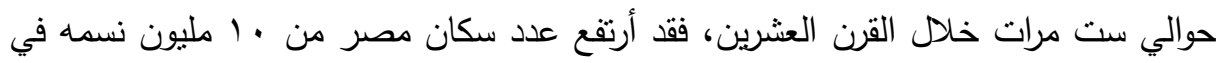

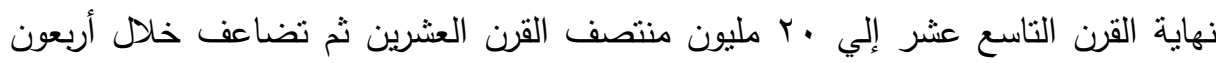

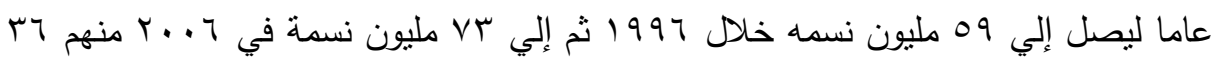

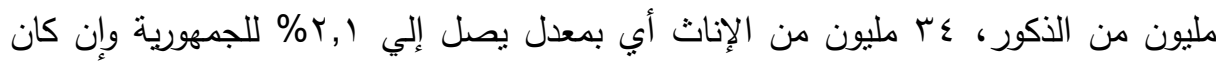

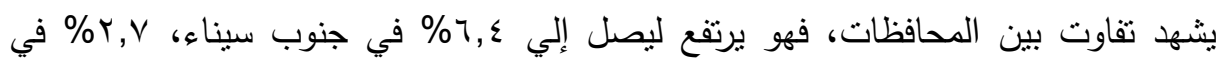

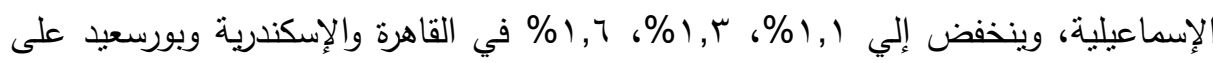

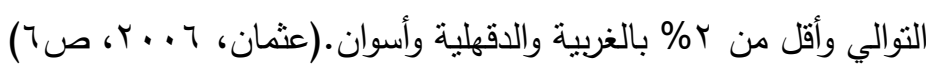
إن أي مجتمع يوجد مركب من العوامل الاجتماعية والاقتصادية والثقافية تلعب أدواراً على المستوى المجتمعي والفردي وتتأثر بالمعايير والقواعد والأعراف السائدة داخل الأسرة والمجتمع، وهذه العوامل نتكل خصائص اجتماعية وديموجرافية وسيكولوجية لها دوراً في ولئي الثأثير في حجم الأسرة المرغوب، وتلعب العوامل البيئية سواء اجتماعية واقتصادية، ودرجة ودائية

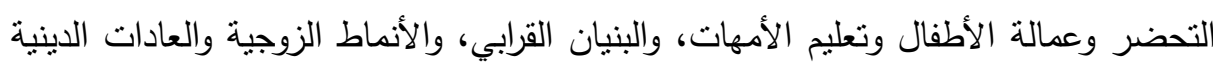

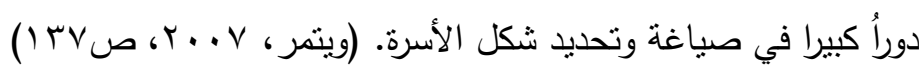
وتختلف معدلات الخصوبة والإنجاب من مكان لأخر وفي المكان نفسه من فتره زمنيه

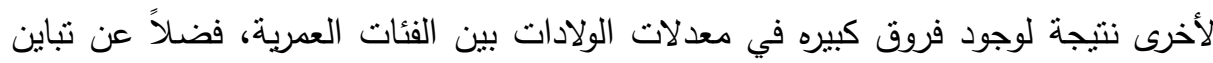

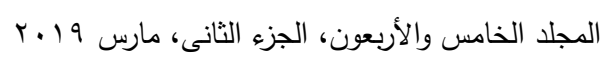


معدلات الولادات حسب محل الإقامة وتباين ذلك بين الريف والحضر والأحوال الاقتصاديه

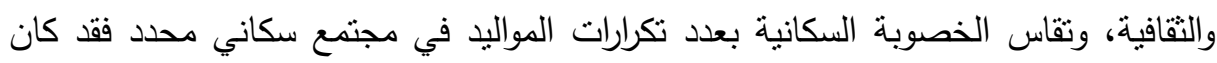
الأساس الرئيسى لقياس الخصوبة هو المؤشر الذي يقبس الإتجاب السنوي وقد كان هذا هو

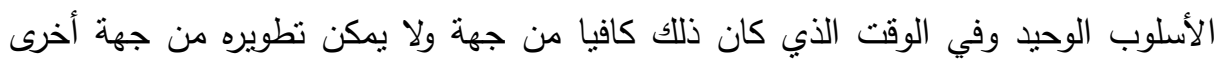

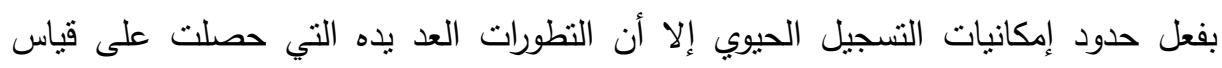

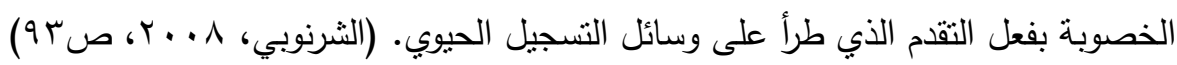
وتعتبر قضية المرأة المصرية بمختلف أبعادها هي قضية المجتمع المصري كله فإذا أردت أن تدرس أوضاع مجتمع من المجتمعات على نحو بليخ وقصير فأبدأ بظروف الأسرة

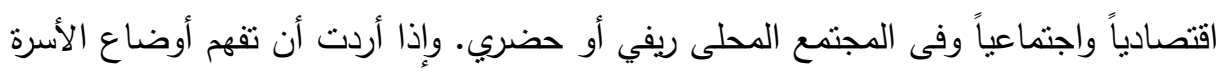

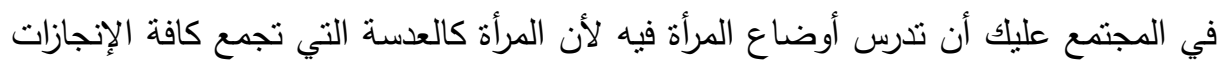

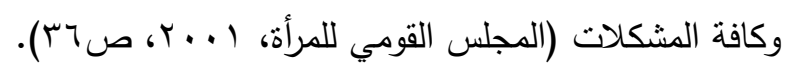

فالمرأة في مصر نصف المجتمع وهى عنصر أساسي لإحداث وتحقيق التتمية، وقد التداثل

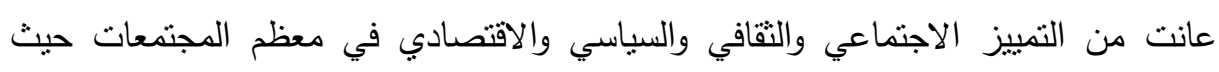

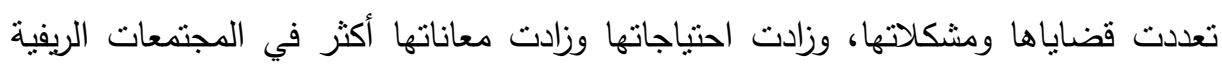

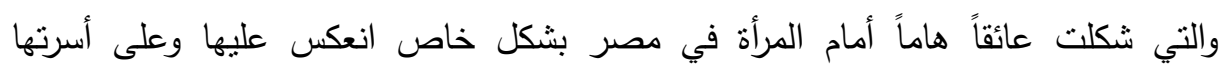

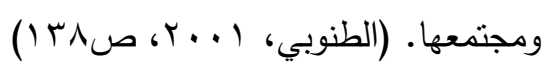

وهو ما دعا إلى ارتفاع الأصوات للاهتمام بالمرأة والنهوض بها وبأوضاعها وتحسين

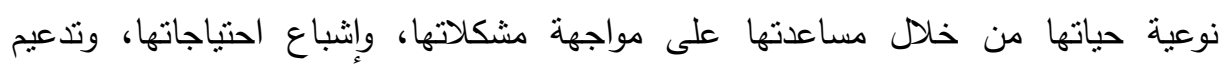

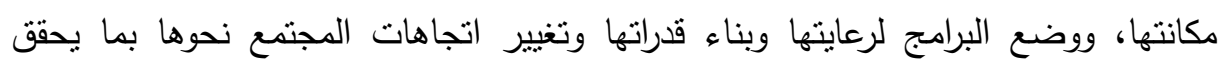

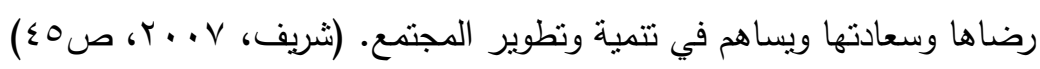

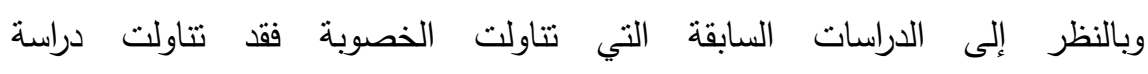

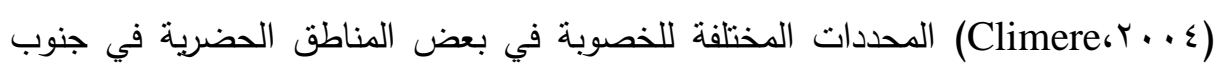
وكانت أهم نتائج الدراسة التوصل إلى أن هناك مستويات من الخصوبة تؤثر في الفتاة التي لم لم فئل

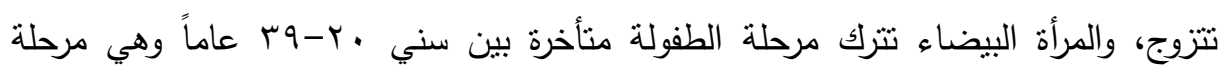

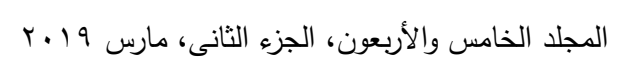


الإنجاب بينما المرأة السوداء تدخل هذه المرحلة من 10-9؛ عاماً، كما وجد أن الخصوبة

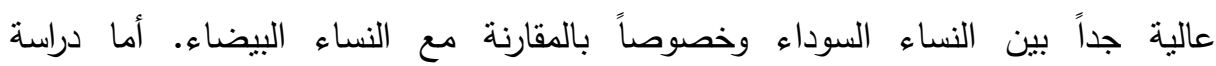

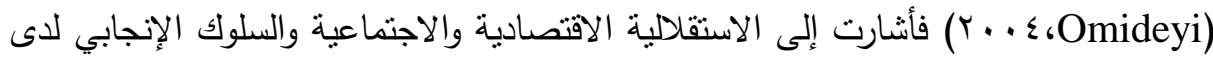

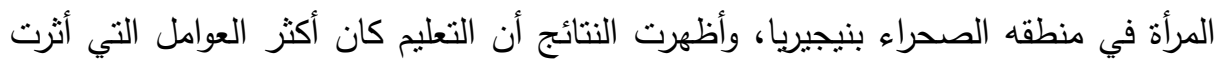
في السلوك. أما الاختلافات الجنسية داخل المخ توضح الاختلافات في الهرمون المؤثر في

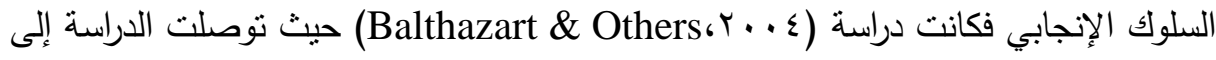
أن السلوكيات الجنسية تتتج من السمات المختلفة للمخ بالمقارنة بتأثيرالاستجابة الحادثة نتيجة

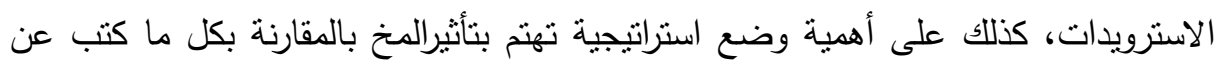

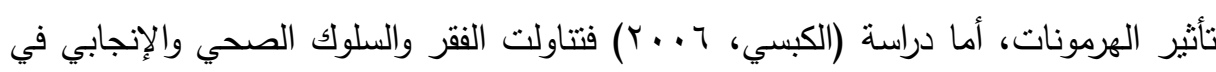
اليمن بهدف الربط بين السلوك الإنجابي والصحي للمرأة اليمنية ومؤشر الفقر الذي ينت احتسابه من خلال البيانات المتعلقة بخصائص المسكن، وأظهرت الدراسة انه كلما زاد الفقر

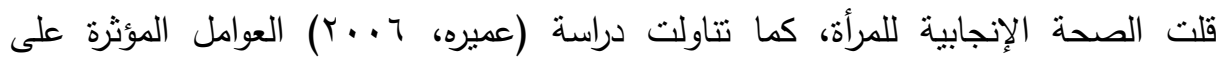
خصوبة دول المغرب العربي، وتهدف هذه الدراسة إلى معرفة الاختلافات بين هذه الدول في

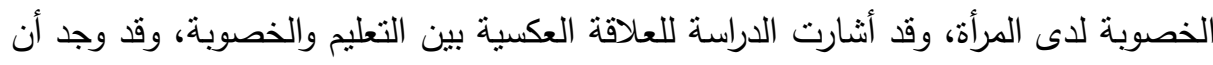
المرأة المتعلمة أكثر وعياً لسلوكها الإنجابي من المرأة غير المتعلمة، أما المرأة غير المتعلمة في الحضر ، فهي قد تتحكم في سلوكها الإنجابي أحسن من منيلتها في الريف.

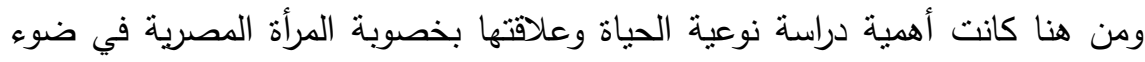

$$
\text { بعض العوامل النفسية. }
$$

\section{مشيلع الكرواسلا}

إن تحسين نوعية الحياة له جانبه الموضوعي وجانبه الذاتي وأهمية تحقيق التكامل بين

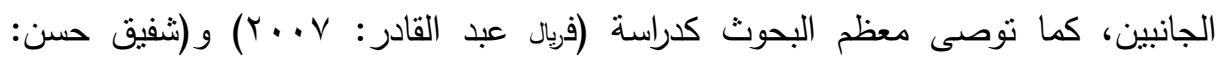

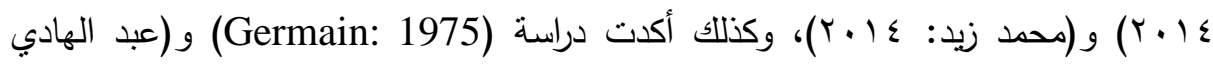

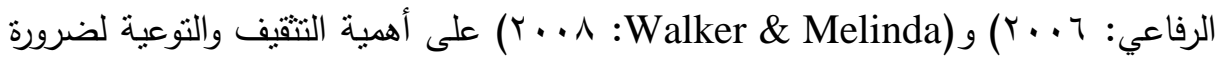
مشاركة وإسهام من يعانون المشكلات في حل مشكلاتهم وإثباع احتياجاتهم وهذا من شأنه 
تحقيق النقة بالذات،كما أن المشاركة في اتخاذ القرارات سواء الخاصة بهن وبأسرهن أو الخاصة بمجتمعهن لها تأثيرها الايجابي في تتمية قدراتهم ومهارتهم وفى إحساسهم بالرضا.

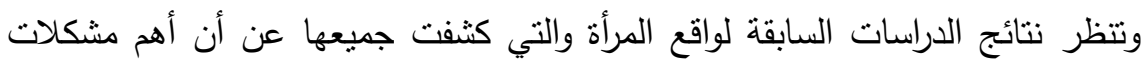
المرأة الريفية تتمتل في مشكلات خاصة بمستوى المعيشة ومشكلات اقتصادية وصحية وتعليمية، وأن تحسين نوعية الحياة له جانبه الموضوعي وجانبه الذاتي وأهمية تحقيق التكامل

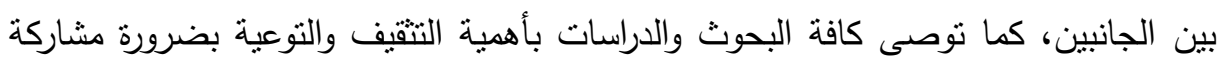

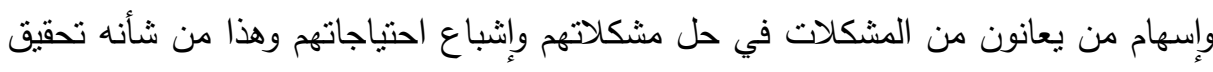

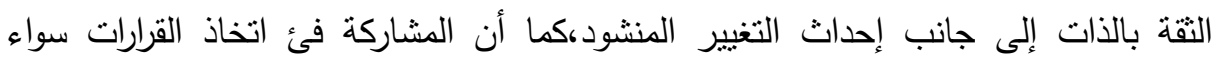
الخاصة بهن وبأسرهن أو الخاصة بمجتمعهن لها تأثيرها الايجابي في تتمية قدراتهم ومهارتهم

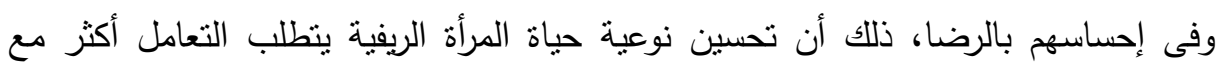

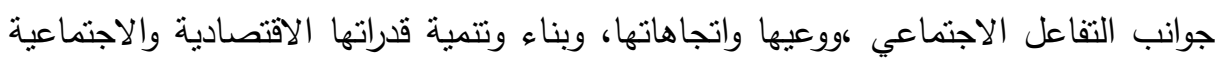

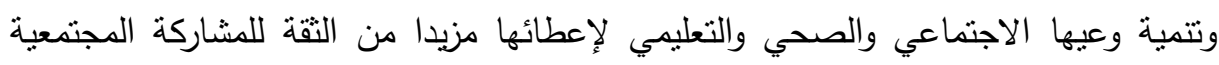

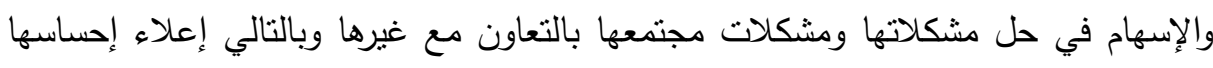

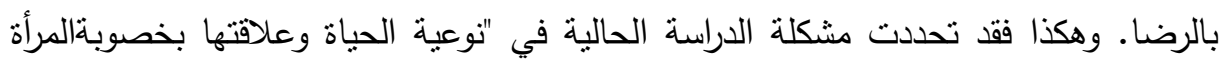
المصرية فى ضوء بعض العوامل النفسية".

\section{تمساولايته الصوراسة}

من خلال العرض السابق لمشكلة الدراسة يمكن وضع التساؤلات التالية: 1 - ما العلاقة بين خصوبة المرأة وبعض المتغيرات الدالة عليها في الريف والحضر؟

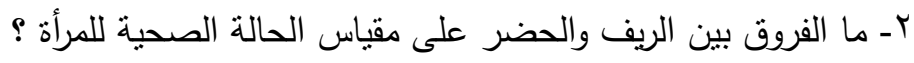

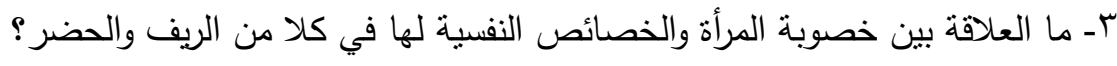

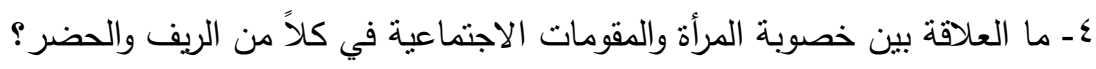




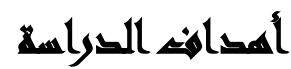

تحاول الاراسة تحقيق الأهداف التالية.

1 - دراسة العلاقة بين خصوبة المرأة وبعض المتغيرات الدالة عليها في الريف والحضر . r - دراسة الفروق بين الريف والحضر على مقياس الحالة الصحية للمرأة.

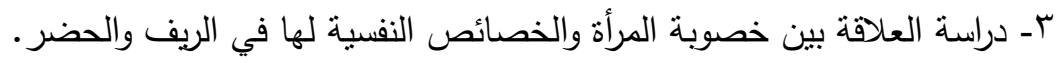
ع- دراسة العلاقة بين خصوبة المرأة والمقومات الاجتماعية في كلاً من الريف والحضر .

\section{أهمية القواسمة}

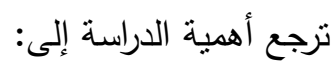

1 - إن هذه الدراسة تهنم بدراسة خصوبة المرأة من خلال دراسة نوعية حياتها. r- إن هذه الدراسة تحاول أن تلقي الضوء على خلى خصوبة المرأة، والتأثثرات المسببة له.

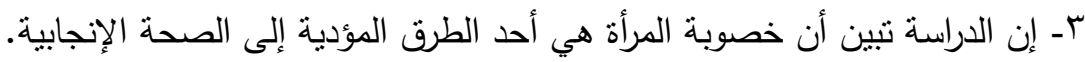

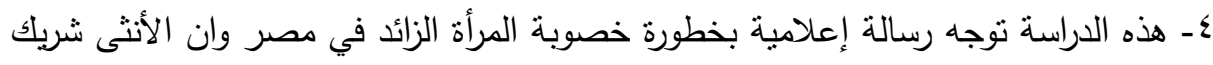
للاجل في اتخاذ قراراته، بما فيها قرار الإنجاب.

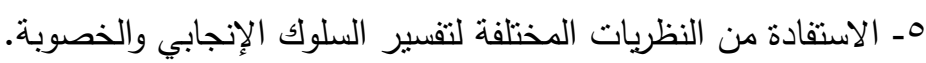

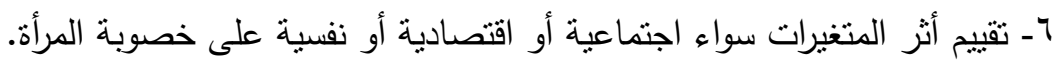

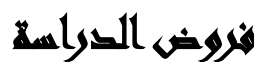

الفرض الأول: "وجود علاقة جوهرية دالة إحصائياً بين خصوبة المرأة وبعض المتغيرات الدالة عليها في كل من الريف والحضر". الفرض الثاني: "وجود فروق جوهرية دالة إحصائياً بين المرأة في الريف والحضر على مقياس الحالة الصحية". الفرض الثالث: "وجود علاقة جوهرية دالة إحصائباً بين خصوبة المرأة والخصائص النفسية

$$
\text { لها في كلا من الريف والحضر". }
$$


الفرض الرابع: "وجود علاقة جوهرية دالة إحصائياً بين خصوبة المرأة والمقومات الاجتماعية في كلاً من الريف والحضر" وجرد عرده

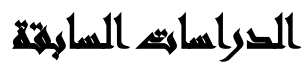

وسوف يتم عرض بعض الدراسات من خلال محورين، محور مرتبط بالدراسات التي

تتاولت خصوبة المرأة، والمحور الثاني بتتاول الدراسات السابقة المرتبطة بنوعية حباة المرأة.

الاراسات التي تناولت خصوية المرأة:

أثارت دراسة (عبد القادر: V. V. P) إلى العوامل المباشرة والغير مباشرة المؤثرة علي

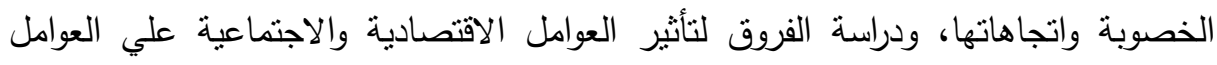

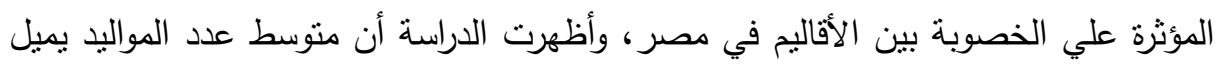

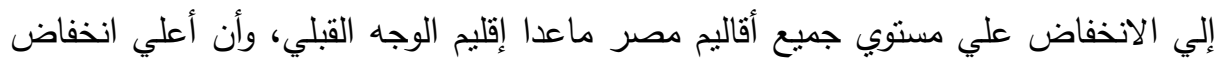

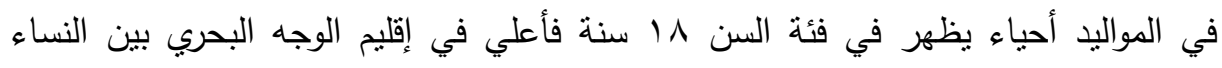

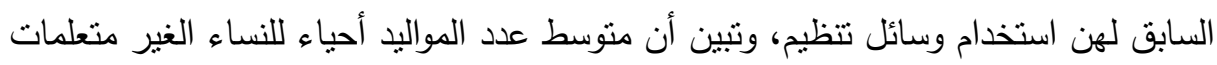

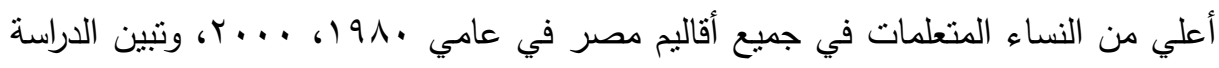
أن ارتفاع السن عند الزواج الأول، وطول فترة الرضاعة الطبيعية والاعتماد عليها، والتعليم

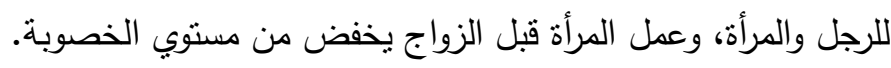

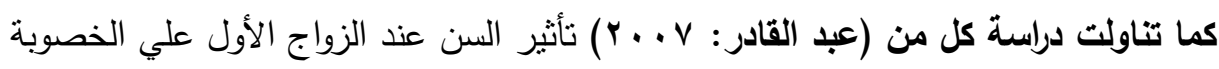

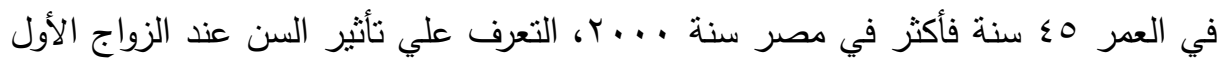
علي الخصوبة في مصر ، وإظهار العلاقة بين السن الوسيط عند الزواج الأول وخصوبة المرأة

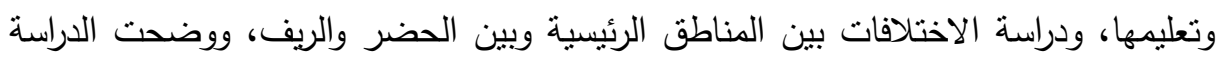

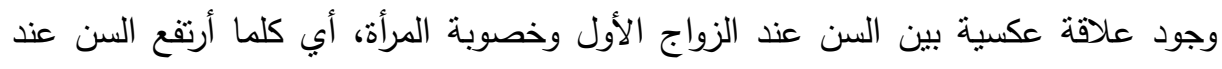
الزواج الأول كلما كانت الخصوبة منخفضة، ووجود علاقة طردية بين السن عند الزئ الزواج الأول وتعليم المرأة، كما أظهرت الدراسة انخفاض خصوبة المرأة بمشاركتها في قوة العمل إذا عالها ما قورنت بالمرأة التي لا تعمل قبل الزواج، وتبين أن السيدات في المحافظات الريفية يتزوجن

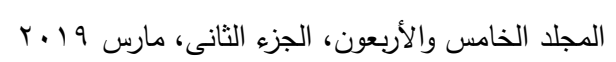


عند أعمار أصغر من السيدات في المحافظات الحضرية، وبالتالي تكون خصوبة السيدات في المناطق الريفية أعلي من خصوبة السيدات في المناطق الحضرية.

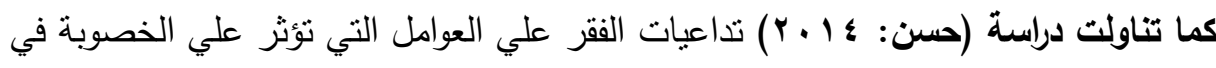

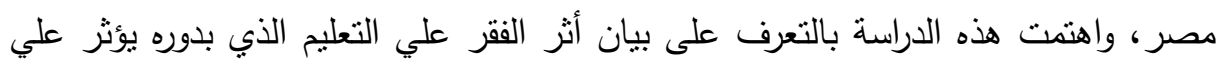

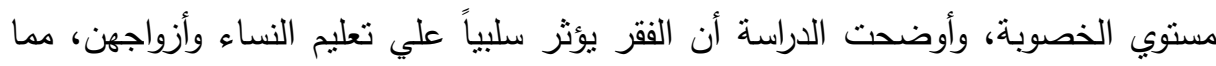

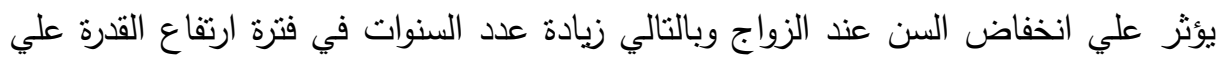

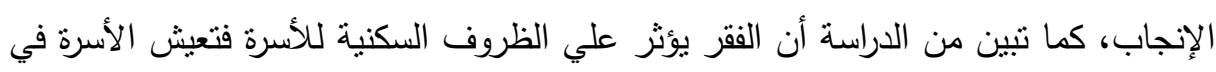

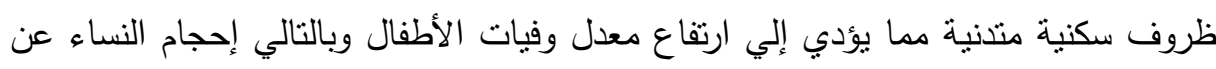

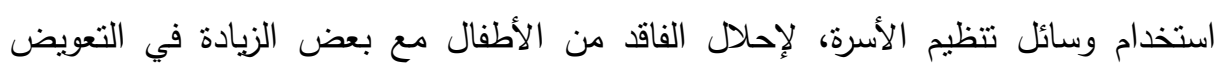
لمواجهة احتمال حدوث وفيات أخري.

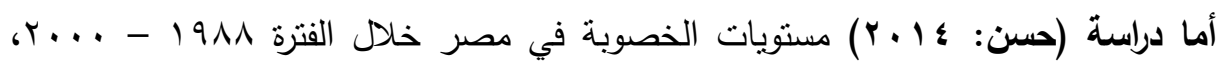
وهدفت الدراسة إلي التعرف علي مستويات الخصوبة الكلية في مصر واتجاهاتها خلال الفترة تللك الفترة، ومعرفة معدلات الخصوبة العمرية والتغيرات التي طرأت عليها خلال نفس الفترة فئية

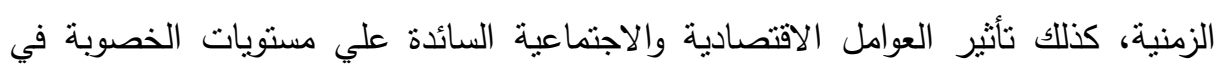

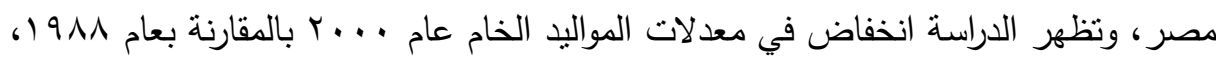

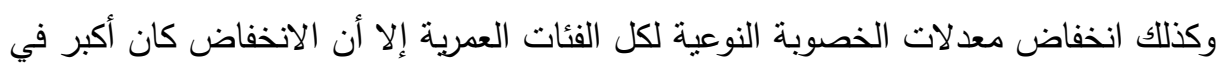

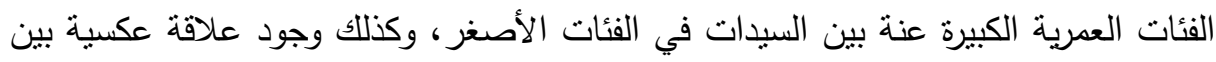
مستوي تعليم المرأة ومعدل الخصوبة الكلية، كذلك وانخفاض مستوي الخصوبة الكلي للنساء العاملات بأجر مقارنة بالنساء اللاتي لا تعملن. الاراسات التي تناولت نوعية حياة المرأة: وأظهرت دراسة (Walker \& Jennifer) 2002) احتياجات نساء الريف ونتشير إلى إلى

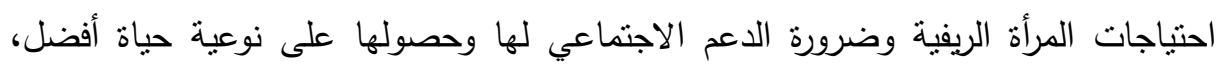

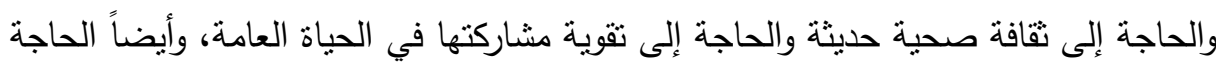
إلى توعية مستمرة لتوضيح أهمية مشاركتها في الحياة الاجتماعية. 
أظهرت دراسة (عثمان محمد: ؟ . . ץ) محاور أساسية لتحسين مستوى المعيشة ونوعية الحياة فى مصر دراسة أن النساء في الريف أكثر تعرضاً لأوضاع المعيشة الصعبة بسبب غياب لهين

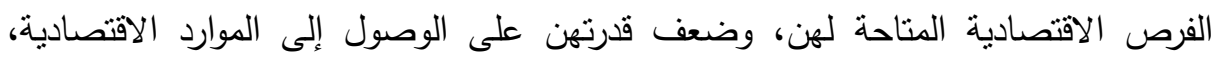
وزيادة معدلات الإنجاب، وضآلة مشاركتهن في عملية صنع واتخاذ القرار وضعف وضعن الأحوال المعيشية للمرأة الريفية والتي يرجع إلى ظروفها ووضعها وضئها التعليمي والاجتماعي.

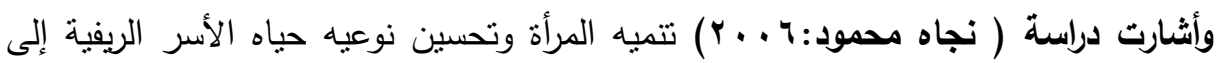
تحديد إسهامات مشروع تتميه المرأة الريفية في تحسين نوعيه حياه المرأة الريفية، وأشارت نتائج الدراسة إلى وجود فروق جوهريه بين متغير تتميه المرأة الريفية لتحسين نوعيه حياه الأسرة

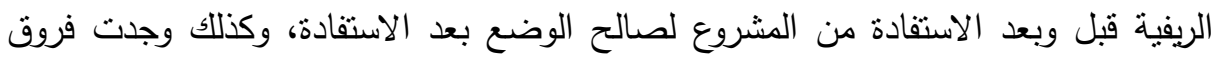

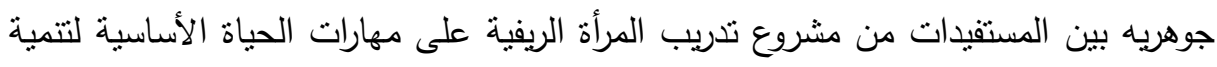
المرأة الريفية قبل وبعد الاستفادة من المشروع لصالح الوضع بعد الاستفادة.

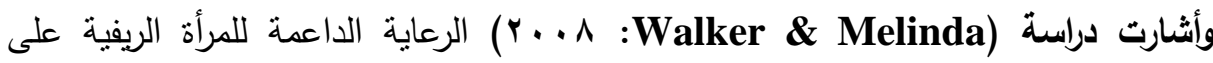
أهمية تحقيق الرعاية النفسية للمرأة الريفية من خلال تطبيق دليل أو مقياس لقياس الاحتياجات

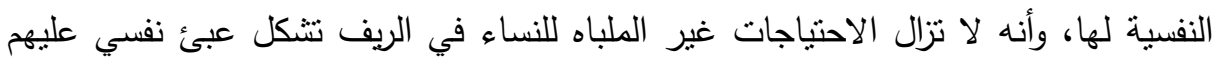
فهم يحتاجون إلى دعم نفسي وذلك يحتاج إلى إحداث تغييرات نقافية إيجابية في إطار نظام للارعاية الاجتماعية والصحية.

وريطت دراسة (هويدا محمد: ^ . . ץ) محو أمية المرأة وتحسين نوعية الحياة كمطلب لتحقيق التتمية المستدامة بين تحسين نوعية الحياة للمرأة كمطلب أساسي وتحقيق التتمية المستدامة من خلال زيادة الاعتماد على نفسها وزيادة علاقاتها الاجتماعية وزيادة شعورها بالرضا عن لوعنه

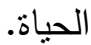
وتناولت دراسة (ناهد صالح: ^ . . ب) مؤشرات نوعية الحياة "نظرة عامة على المفهوم والمدخل مؤشرات نوعية الحياة حيث توصلت إلى وجود بعدين أساسيين لمؤشرات نوعية الحياة هما البعد الموضوعي المعتمد على المؤشرات النوعية في رصد نوعية الحياة وهى (الصحة، 
التعليم، العمل، والطلب على السلع والخدمات)، والبعد الذاتي المعتمد على أحكام الأفراد ومدى شعورهم بالسعادة عن نوعية حياتهم.

التعقيب العام على الدراسات السابقة:

نجد انه فى اطار ما نم الرجوع اليه من دراسات وبحوث ميدانية تنتاول المرأة وتحسين نوعية الحياة لها فقد اتضح ما يلي: • وجود مشكلات تعانى منها المرأة تتلخص فى مشكلات مادية تتمثل فى نقص وقصور فى الفى

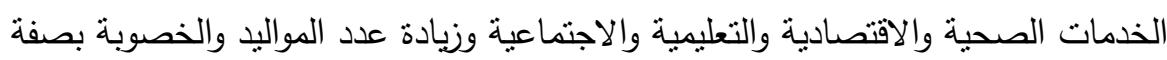

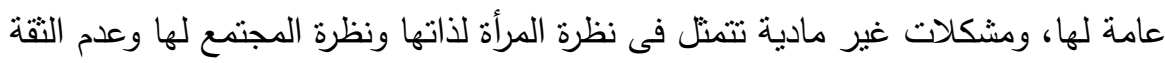
فى نفسها وانخفاض تقديرها لذاتها وعدم الرضا والسعادة عن حياتها.

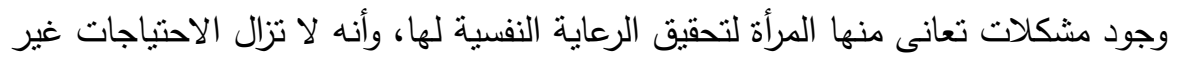

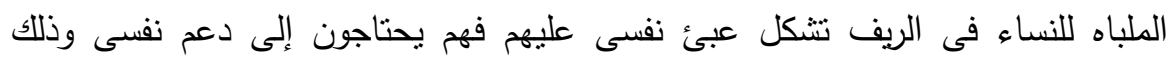
يحتاج إلى إحداث تغييرات ثقافية إيجابية فى إطار نظام للرعاية الاجتماعية والصحية.

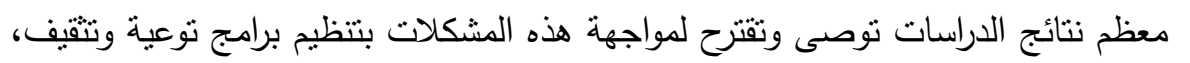

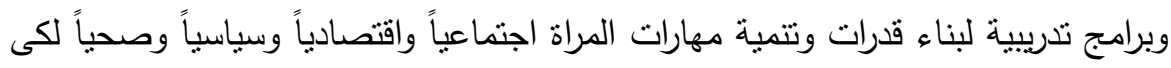
تحل مشكلاتها ومشكلات مجتمعها المحلى بالاعنماد على جهودها الذاتية ومشاركتها أو ونيأي يكون لها صوت مسموع فى صنع القرارات المجتمعية التى تجبر السياسيين على اعطاء اولوية لتوفير الخدمات المختلفة التى تتقصها فى مجتمعها أو ضرورة فئى نمكينها اقتصادياً واجتماعياً وسياسياً. اهتمام كافة الباحثين بكلا البعدين الموضوعى والذاتى فى تحسين نوعية حياة المرأة وان كانوا يختلفون بالنسبة للأولوية لكن الاتجاه العام هو تحقيق التكامل بين البعدين.

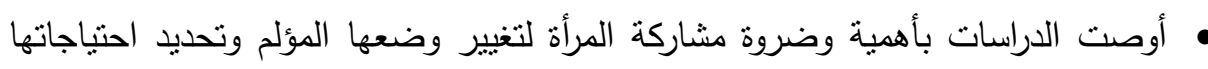

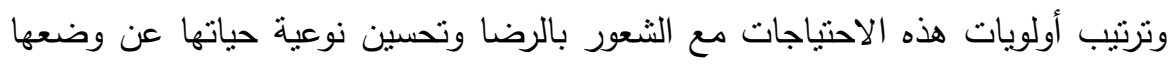
الحالي. 


\section{الاطار النظظيه للقراسمة}

تعتبر عملية الخصوبة والإنجاب من أهم الوظائف التي خلقها اله للمرأة والتي أهلها بدنيا ونفسيا من اجل القيام بهذه العملية ويعتبر الزواج هو الثنل الأفضل للقيام بهذه العملية من

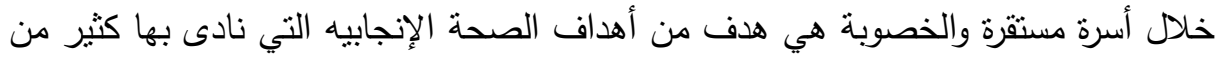
المؤتمرات السكانية والتتموية، والذي يتمنل في مساعدة الأزواج والأفراد على تحقيق الأهداف

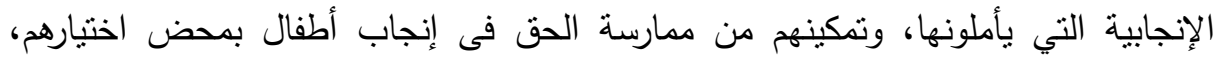

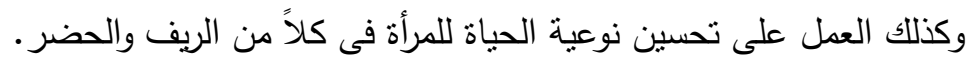

ويرتبط السلوك الإنجابي بالخصوبة لدى المرأة، والذي يعتبر مؤشر للرعاية الصحية إثثاء لهرئ فترة الحمل، وهذا المؤشر من أهم المؤشرات التي يمكن الاعتماد عليها لقياس الخصوبة، لئه فبينما يحصل أكثر من تلثي النساء في المناطق الريفية على الرعاية قبل الولادة فان زهاء • 9 من نساء الحضر يحصلن على هذه الرعاية كما أن نسبة الطلب على استخدام وسائل

$$
\text { تتظيم الأسرة مؤشر أخر لقياس الخصوبة لدى المرأة. }
$$

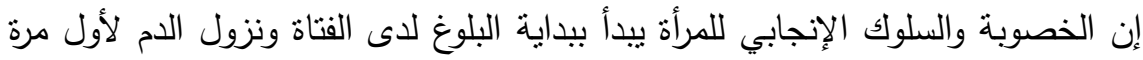

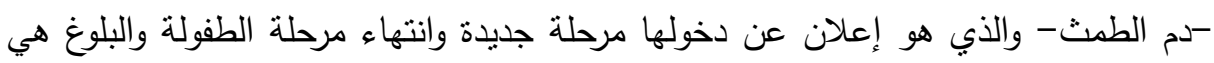
المرحلة التي تتطور فيها وظائف الجهاز التتاسلي ليقوم بوظيفته التتاسلية أى الممارسة الجنسية والإنجاب وهو يعتبر عن النضوج الجنسي وما يصاحبه من تغيرات جسمية ونفسية

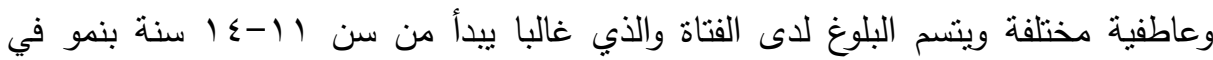

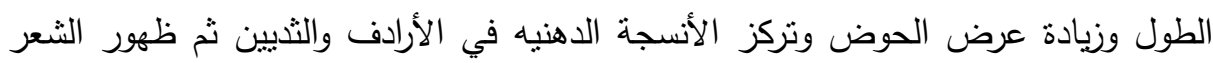

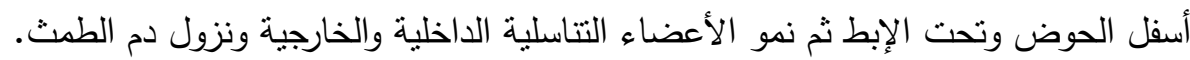
إن خصوبة المراة وسلوكها الإنجابي ونوعية حياتها يتضمن حق المرأة في أختاه أختيار

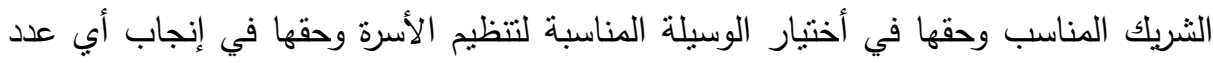

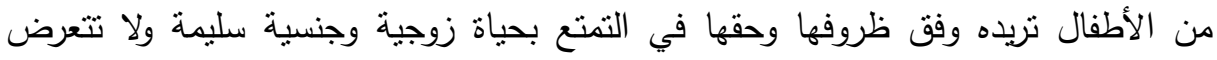
للإجهاض أو العقم أو للزواج المبكر لتجنب الأمراض الجنسية ومضاعفات الحمل واعتلال الصحة ووفيات الأمهات نتيجة للحمل والنفس وذللك لتحسين نوعية حياتها.

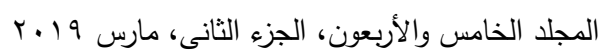


الموجهات النظرية للاراسة:تثثل المنطلق النظري لهذه الدراسة في: نظرية الضغوط: الافتراضات التي تقوم عليها نظرية الضغوط البيئية:

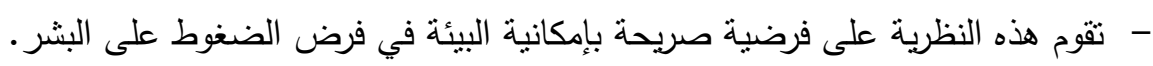

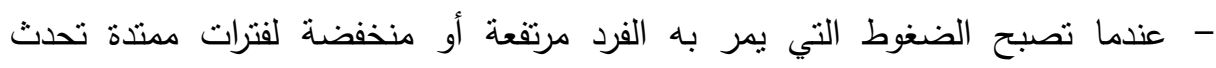
الضغوط.

- إن هذه الضغوط تحدث عندما لا تتلاءم المنطلبات البيئية مع قدرة البشر .

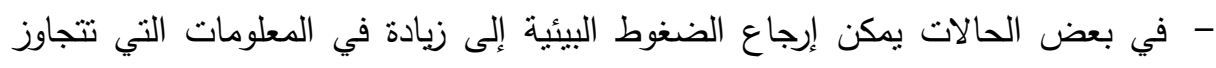
الإمكانيات الخاصة بالانتباه لدى الفرد.

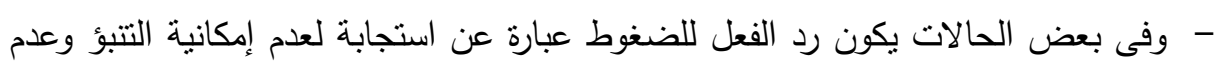
إمكانية السيطرة الددركة للبيئة.

- نؤدى الضغوط إلى أن يشعر الفرد بالعجزعلى مواجهة الموقف.(Cohen,1980)

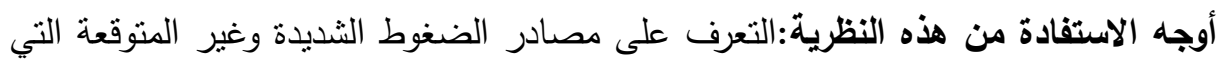

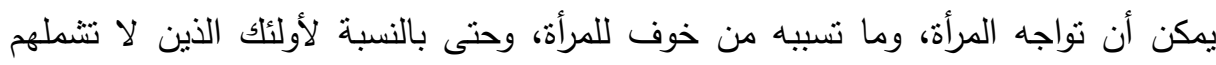

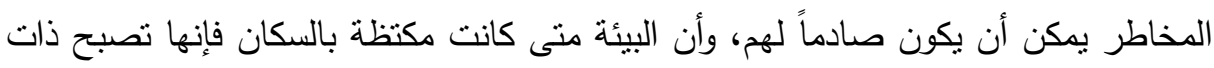

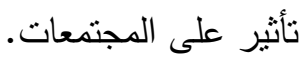

\section{هخاهيهر التواسة}

أ- مفهوم نوعية الحياة: تعرف نوعية الحياة بأنها "درجة الحاجة إلى الرضا داخل

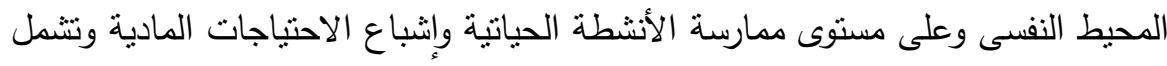

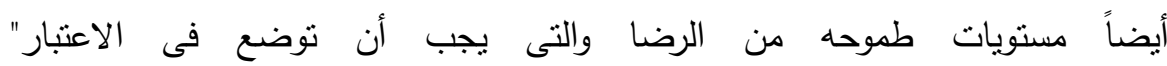
(,Seemar..r.p. 145).

أو أنها " المؤشرات الكيفية والكمية ومدلولاتها للأوضاع والظروف الاجتماعية والصحية والاقتصادية، والتفاعل بين هذه الظروف وانعكاساته على درجة إنتاجية الفرد ومشاركته

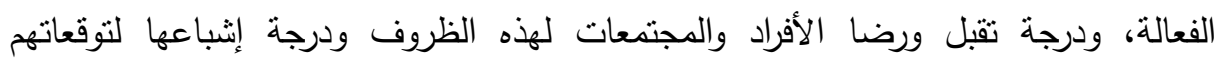

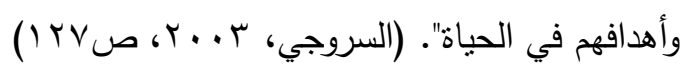

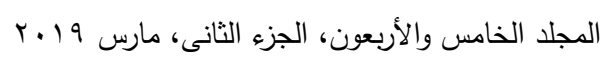


ويمكن تعريف نوعية الحياة إجرائياً بأنها: هي مجموعة المؤشرات الاجتماعية والاقتصادية والصحية المؤثرة في حياة البشر.

ب- مفهوم الخصويةة: تعرف بأنها " قدرة المبيض على إنتاج بويضات خلال فترة زمنية أو خلال حياتها، تكون جاهزة للتلقيح من الحيوان المنوي للرجل". (جان كهن وآخرون،

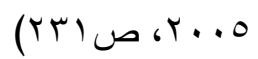

ويمكن تعريف الخصوية إجرائياً بأنها: هي الفترة الزمنية التي نتشط فيها المرأة جنسياً وتقاس

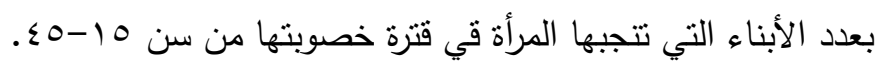

ج- مفهوم العوامل النفسية: وتعرف بأنها "نظام منكامل من السمات أو الخصائص من ستره العقلية أو السلوكية التي تميز شخصاً ما، وتؤلف هذه السمات الهيكل النفسي للإنسان،

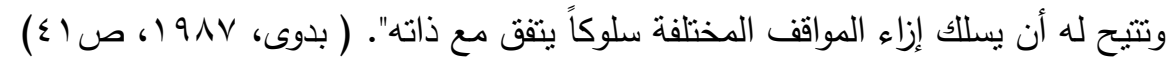

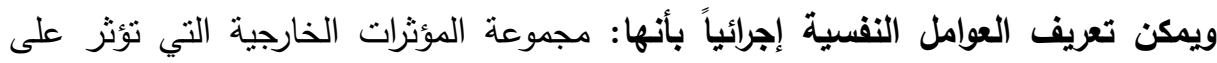
سلوك وشخصية الفرد وتتكل مجموعة من السمات النفسية والعقلية والسلوكية ويمكن تحديد درجة العوامل النفسية من خلال درجة المبحوثين على مقياس العوامل النفسية.

\section{الإجباءايت المنهيجية للترواسة}

نوع الاراسة: تتنمي هذه الدراسة إلى نمط الدراسات الوصفية لكونها أنسب أنواع الدراسات ملائمة لطبيعة موضوع الدراسة والتي تهدف إلى دراسة العلاقة بين متغيرين متغير مستقل وهو

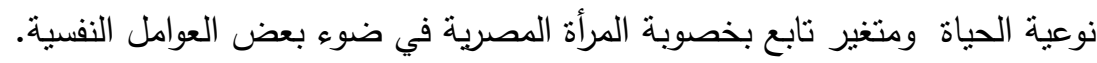
منهج الاراسة: نتتهج الدراسة الحالية منهج المسح الاجتماعي بالعينة ذلك أن منهج المسح

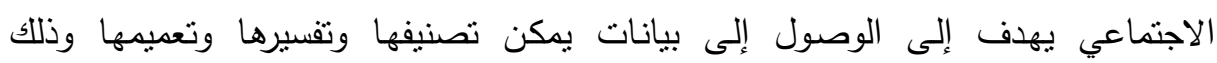
للاستفادة بها في المستقبل وخاصة في الأغراض العلمية. ويتمثل المنهج المستخدم في: المسح الاجتماعي بالعينة للسيدات في سن الخصوبة بمجتمع الدراسة. أدوات الاراسة:اعتمدت الدراسة الراهنة على الأدوات التالية: - مقياس نوعية الحياة من إعداد الباحث. 
- مقياس العوامل النفسية المؤثرة في خصوبة المرأة من إعداد الباحث. تصميم أدوات الدراسة

أ- مقياس نوعية الحياة:شمل مقياس نوعية الحياة على ثناث مؤشرات رئيسية تقيس نوعية الحياة وهى مؤشر الحالة الاجتماعية، ومؤشر الحالة الاقتصادية، ومؤشر القدرات الحياتية نواتية

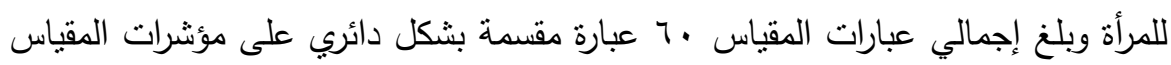

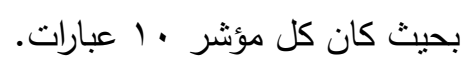

ولقد اعتمد الباحثون في التأكد من ثنات المقياس على طرات طريقة ( إعادة الاختبار) حيث قام الباحث بتطبيق المقياس على عينة من السيدات في عمر الخصوبة وعددهم (•r) مفردة،

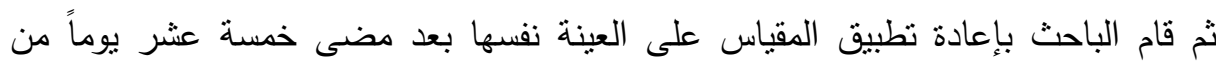

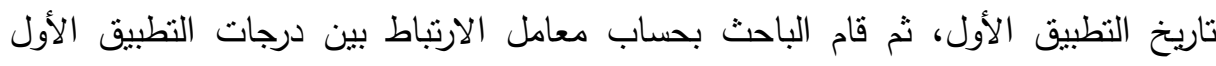

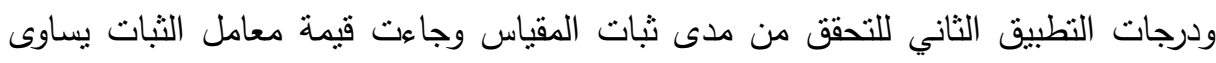

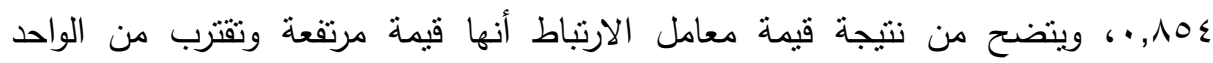

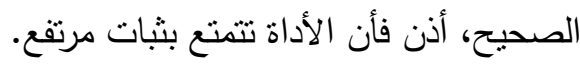
- صدق المقياس: تم استخدام التحليل العاملي كأسلوب أمتل للتحقق من صدق التهب التكوين أو الصدق البنائي للأداة. وقد قام الباحث بحساب التحليل العاملي بطريقة المكونات الأساسية

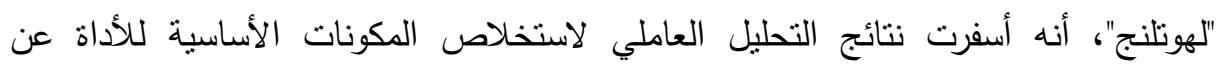

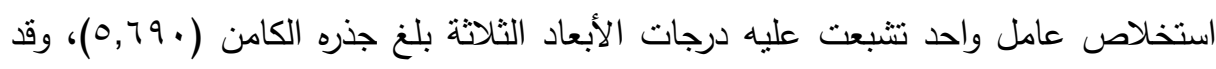
استقطب العامل نسبة ؟ . .. ـ9 \% من التباين الكلي للمصفوفة الارتباطين. - ثبات المقياس: نم حساب ثبات المقياس على عينة الدراسة الحالية من خلال التجانس

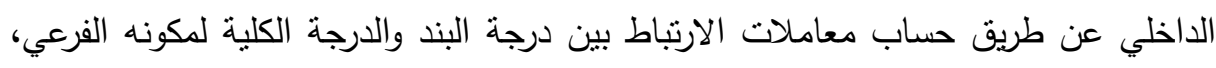
ومعاملات الارتباط البينية للمقاييس الفرعية. وكذلك معامل ارتباط كل مقياس فرعى بالمجموع لإنه الكلى للمقياس كما يبين الجدول التالي. 
جدول (1): معاملات الارتباط المنبادلة بين درجة البند والدرجة الكلية لمكونه الفرعي لمقياس

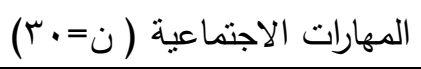

\begin{tabular}{|c|c|c|c|c|c|}
\hline \multicolumn{2}{|c|}{ القدرات الحياتية } & \multicolumn{2}{|c|}{ الحالة الاقتصادية } & \multicolumn{2}{|c|}{ الحالة الاجتماعية } \\
\hline الارتباط & البند & الارتباط & البند & الازتباط & العبارة \\
\hline$\cdot 60 \cdot 1 * *$ & r & . 6 OYY*** & r & $\cdot$. $\Lambda \cdot \sum * *$ & 1 \\
\hline . ‘乞.।** & 7 & $.0010 * *$ & 0 & . .VOY*** & $\varepsilon$ \\
\hline . ، $\Sigma 79 * *$ & 9 & $.00 \wedge \Gamma^{* * *} *$ & $\Lambda$ & . 6 Y $\Lambda$ N * * & $\mathrm{V}$ \\
\hline . 6 & Tr & $.0040 \% *$ & 11 &. . $\vee 9 V^{* * *}$ & 1. \\
\hline$\cdot 60 \leqslant \Lambda^{*} *$ & 10 & $.099 \% *$ & $1 \varepsilon$ & 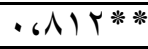 & $\pi$ \\
\hline $.6047 * *$ & 11 & $\cdot$ * $\left.\sum \Lambda\right)^{*} * *$ & IV & . VOY * * & 17 \\
\hline $.60 \%$ * * * & YI & $.60 \mathrm{V0} * *$ & r. & 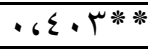 & 19 \\
\hline . เह११*** & $T \varepsilon$ & . ، & $\overline{T M}$ & $.6 r V Y^{*} * * * 3$ & YY \\
\hline $.60 \mathrm{VV} * *$ & TV & $.6 \mathrm{OVY} * *$ & YT & $.6 \vee 77 \% *$ & TO \\
\hline $.60 .1 \% *$ & $r$. & $.60 \mathrm{~V} \leqslant * *$ & rq & $\cdot . \mathrm{V} \cdot \mathrm{V} * *$ & rA \\
\hline
\end{tabular}

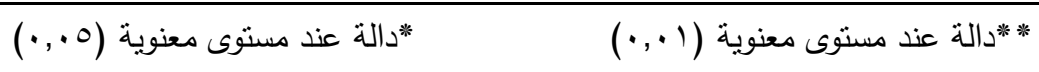

اتضح من الجدول السابق أن جميع معاملات الارتباط بين كل البنود ومكوناتها الفرعية

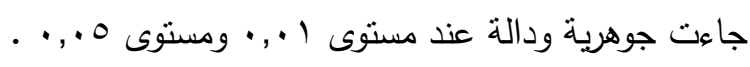

ب- مقياس العوامل المؤثرة على خصوية المرأة: شمل مقياس العوامل النفسية المؤثرة في خصوبة المرأة على اربعة مكونات وهى (الحالة الصحية، الحالة الاجتماعية، الحالة

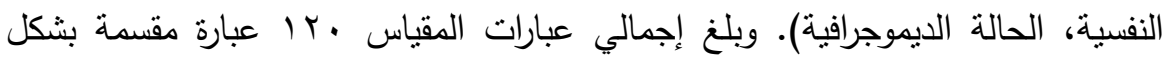

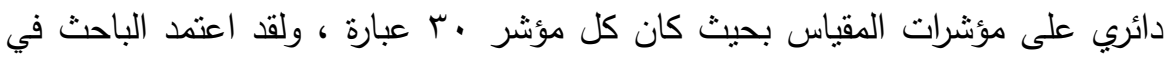

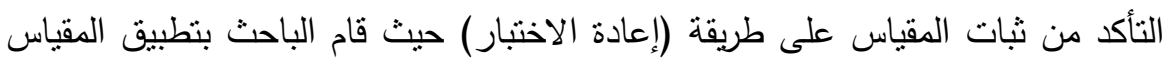

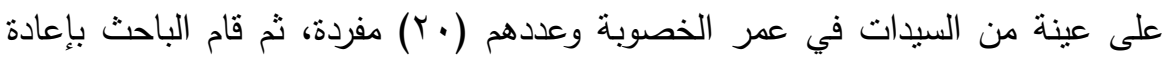
تطبيق المقياس على العينة نفسها بعد مضى خمسة عثر يوماً من ناريخ التطبيق الأول،

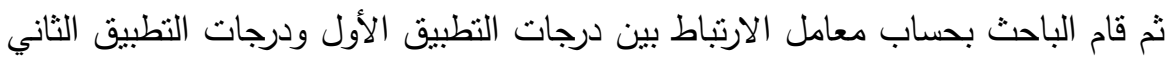

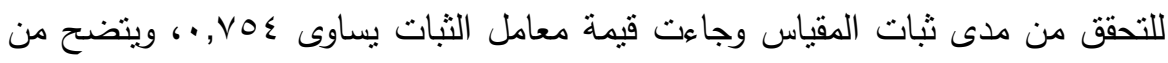
نتيجة قيمة معامل الارتباط أنها قيمة مرتفعة وتقترب من الواحد الصحيح، أذن فأن الأداة تتمتع بثبات مرتفع. 
- ثبات المقياس: نم حساب التجانس الداخلي للمفردات عن طريق حساب معاملات الارتباط

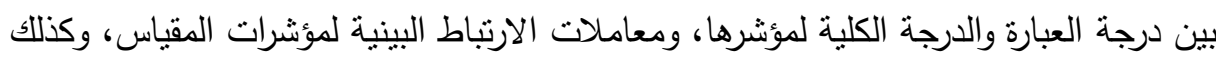

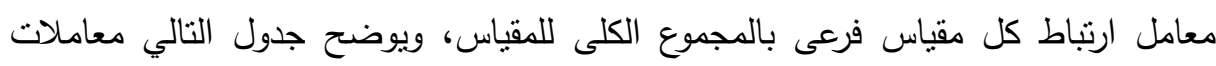

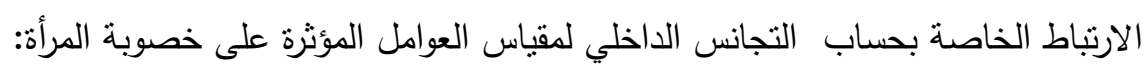
جدول (Y): معاملات الارتباط المنبادلة بين مؤشرات مقياس العوامل المؤثرة على خصوبة العية

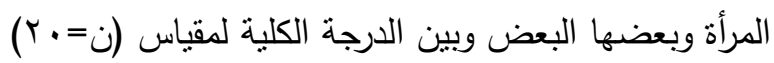

\begin{tabular}{|c|c|c|c|c|c|}
\hline 0 & $\varepsilon$ & $r$ & $\bar{r}$ & 1 & المتغيرات \\
\hline ***.6909 & 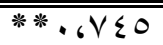 & "**. .9 $9 \leqslant 1$ & ***.6901 & - & 1- الصحية \\
\hline$* * .6917$ & ***. เVฯ & $* * .6940$ & - & & ب- الاجتماعية \\
\hline$* *$ * .9V. & ***،八ミ7 & - & & & r- النفسية \\
\hline **. . Vฯ. & - & & & & ع- الديموجرافية \\
\hline- & & & & & 0- الدرجة الكلية \\
\hline
\end{tabular}

يتضح من الجدول أن جميع معاملات الارتباط بين مؤشرات المقياس موجبة ودالة دالة

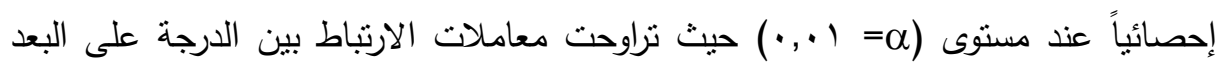

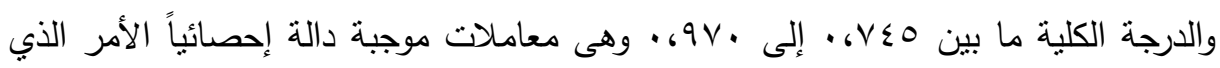
يعكس التجانس الداخلي للمقياس.

\section{هجالاهي القراسلا}

تحددت مجالات الدراسة في المجال المكاني والبشري والزمني وذلك على النحو التالي: المجال المكاني:قام الباحث باختيار المجال المكاني للدراسة على النحو التالي: تم إجراء الدراسة في وحدات صحية في منطقتين أحدها ريفية والأخرى حضرية وقد باتئ

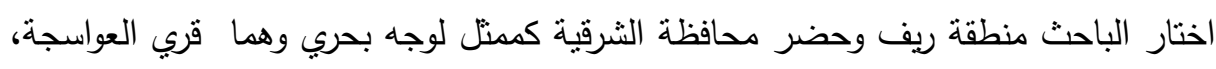

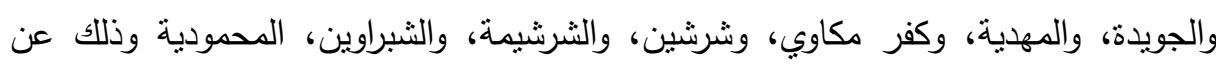

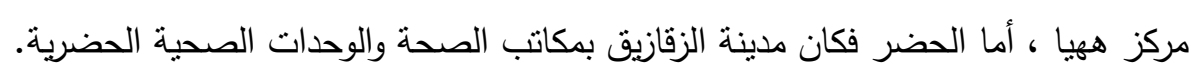

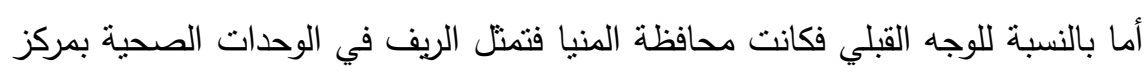
"أبو قرقاص"، أما بالنسبة للحضر فتمثل بالوحدات الصحية بمدينة المنيا. 
المجال البشري:تمثل المجال البشري للاراسة الحالية على النحو التالي: • عينة عشوائية بسيطة وبلغ حجم العينة في حضر الوجه القبلي (Y) ( مفردة وحضر

$$
\text { الوجه البحري (10 أبنه ) مفردة. }
$$

أما بالنسبة لريف الوجه البحري فتم احتيار عينة عشوائية بسيطة بلغت (9 1 (1) مفردة في

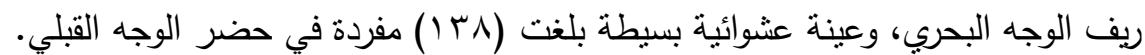

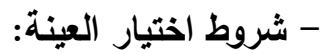

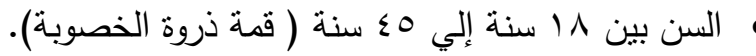

• أن يترددون على مراكز ووحدات الرعاية الصحية للحصول على خدماتها المختلفة ويتم تطبيق الاستمارة داخل مكاتب وعيادات تتظيم الأسرة بالوحدات الصحية. • هذه الاستمارة نطبق على كلا من السيدات المتزوجات وفي سن الإنجاب لأن المتزوجات أكثر تقديراً ووعياً بجوانب السلوك الإنجابي وخاصة فيما يتعلق بتفاصيل العلاقة الحميمة بين الزوجين، كذلك على الفتيات اللاتي لم يتزوجن فيطبق عليهن الاستمارة بشروط لأنها

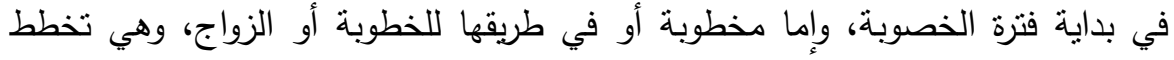
لاختيار أفضل وقت للإنجاب وتحدد مع شريكها عدد الأطفال ، أما أقل من هذا السن

$$
\text { فيصعب التكلم معه نظراً للعادات والثقاليد والخجل الطبيعي أو لعدم المعرفة. }
$$

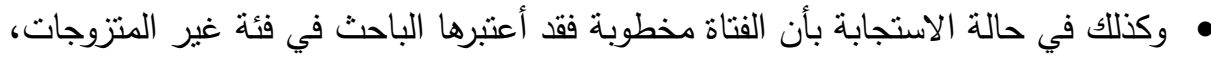
و كذللك التي هي حامل لا يعتبر حملها طفل ثان ما دام لم يولد، وكذللك عند الاستجابة من بعض السيدات بأن الزواج عرفي أعتبره الباحث زواج صحيح، وأي نوع من أنواع

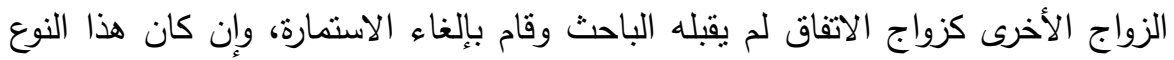
أقتصر على ه استمارة من إجمالي الاستمارات.

\section{خصائص العينة: من حيث:}

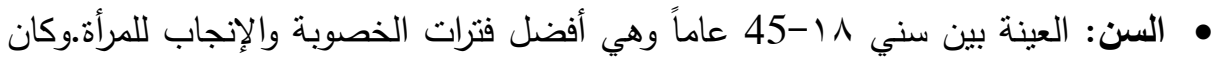

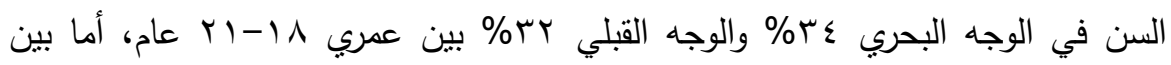

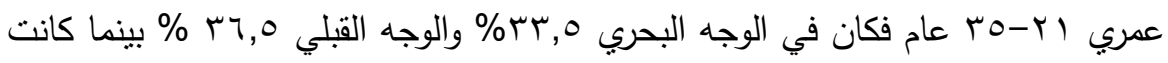

$$
\text { المجلد الخامس والأربعون، الجزء الثانى، مارس } 19
$$




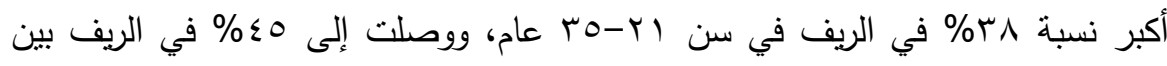

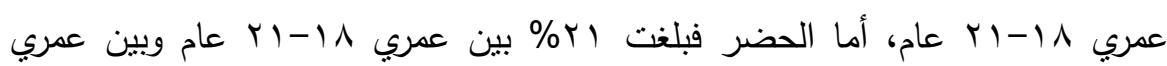

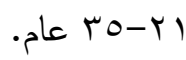

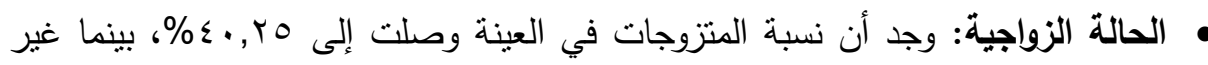

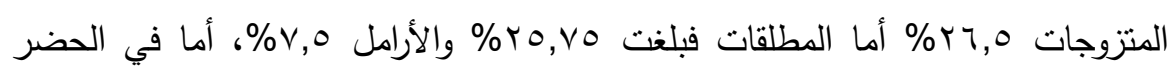

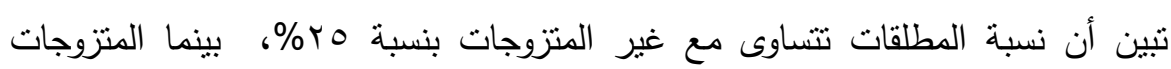
\% 1,0 • السن عند الزواج: اتضح أن أكبر نسبة لسن الزواج هو أقل من 17 عام وهو السن الذي

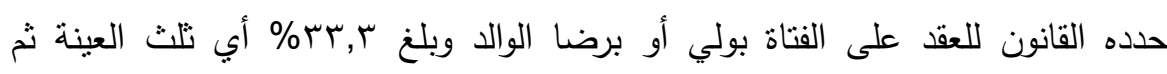

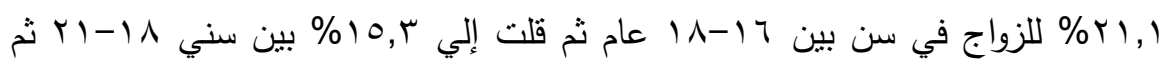

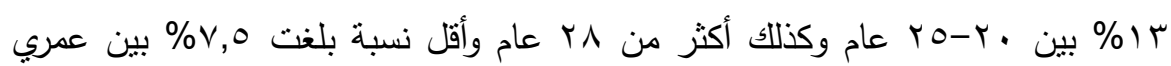

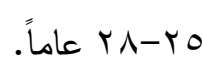

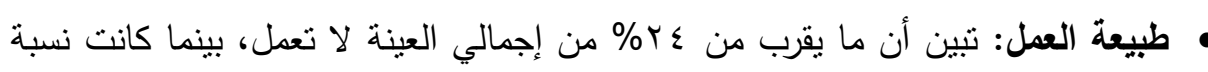

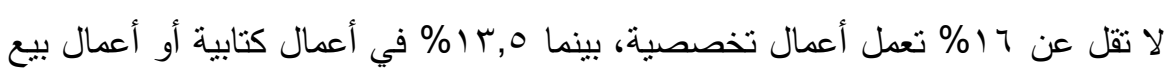

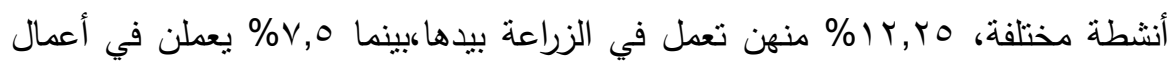
بدوية، والباقي كان يعمل في الحضانات ومشرفات للأطفال. • استخدام وسيلة تنظيم الأسرة: وجد أن هناك .,90\% من العينة لا نستخدم أي وسيلة

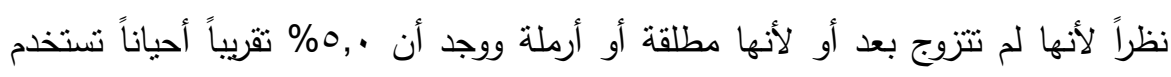

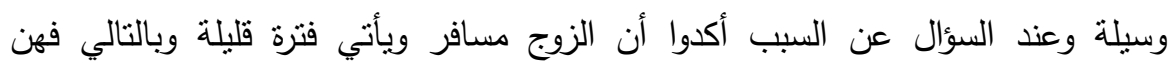
مستخدمات مؤقتات حتى لا تزيد من وزنها لاستخدام حبوب منع الحمل أو لزيادة نسبة ولته الدم باستخدام اللولب. • رغبةالأسر في تعليم أبنائها: اتضح إصرار المبحوثين في الريف والحضر على استمرار

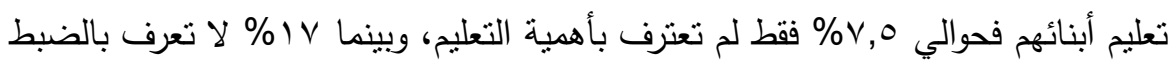

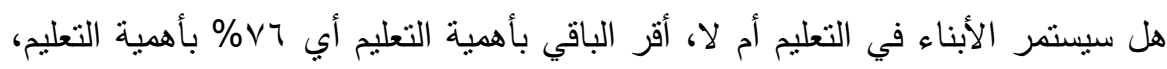


والملفت للنظر أن الوجه القبلي كان أكثر إصراراً على تعليم الأبناء، وعند السؤال عن أسباب ذلك ذكروا ضيق ذات اليد وضرورة مساعدة الأسرة، والحالة الصحية وغير ذلك.

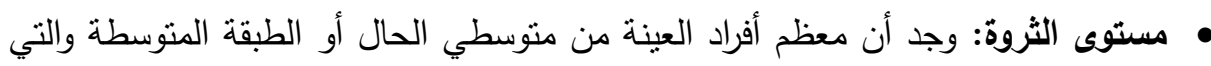
تمنلك مرتباتها بجانب بعض الدخل الإضافي، أما الباقي فكان من الفقراء ذوي الدوني الدول

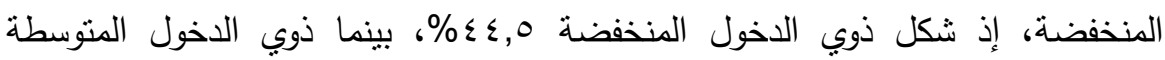

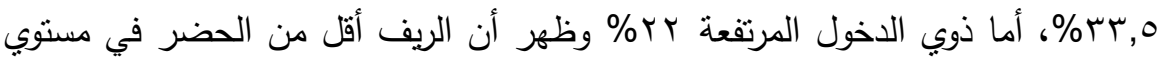

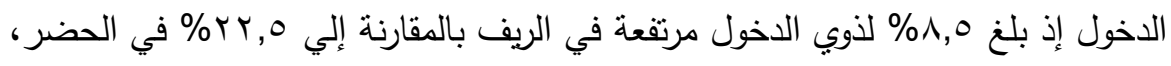

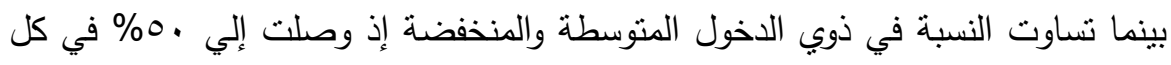

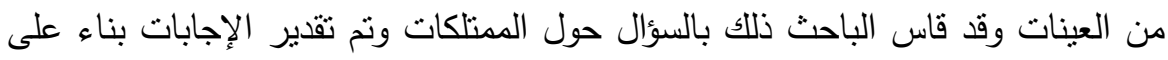
الثزوة أو الملكية.

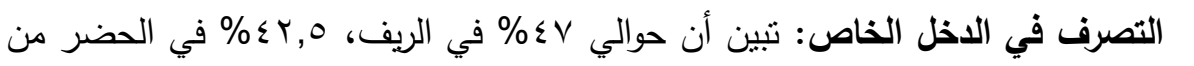

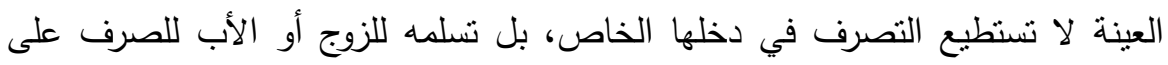

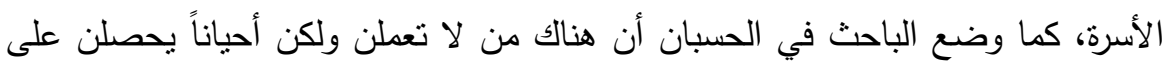
دخل خارجي، فتم تصنيفهم حسب التصرف في الدخل. الشعور بضغوط الحياة: وجد أن هناك إحساس بالثعور بضغوط الحياة وهي في الريف

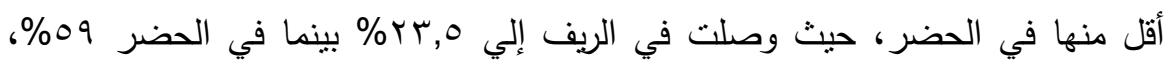
بينما كان الإحساس إلي حد ما في الريف ه,rr\% مقارنة بالحضر الذي وصل إلى إلى إلى ابץ\%، وكان أعلى إحساس بالضغوط في حضر الوجه البحري، ثم حضر الوجه القبلي.

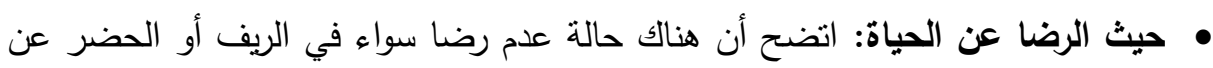

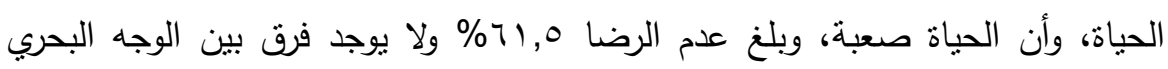
والقبلي في هذا الخصوص.

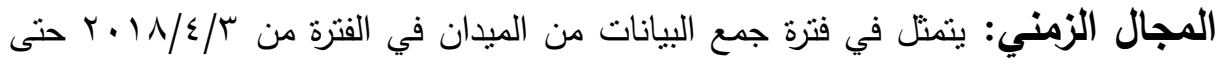
$. r \cdot 1 \Lambda / T / \Lambda$ 
المعاملات الإحصائية المستخذمة: بعد جمع البيانات ومراجعتها، تم تقريغ البيانات آليا باستخدام برنامج SPSSv1.6، وتم

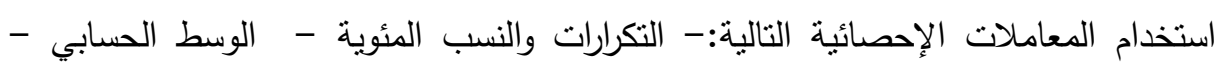
الانحراف المعياري - تحليل التباين الأحادي (اختبار ف) one way anova .- معامل

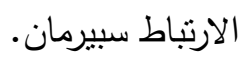

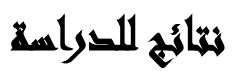

الفرض الأول: "من المتوقع وجود علاقة جوهرية دالة إحصائياً بين خصوبة المرأة وبعض الرض

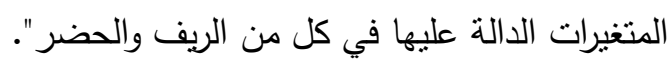


مجلة العلوم البيئية

معهد الدراسات والبحوث البيئية - جامعة عين شمس لئس

جدول (ץ): يوضح الفروق بين الحضر والريف على مقياس الخصوبة

\begin{tabular}{|c|c|c|c|c|c|c|c|c|c|c|c|c|}
\hline & لمالى & الإج & & & القب!ي & الوجه & & & البحري & الكوجه & & \\
\hline ف & & غر & & ف & 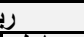 & $\mu \dot{\mu}$ & & ف & 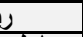 & $\dot{~}$ & & العلاقة \\
\hline الدلالة & الإرتباط & الدلالة & الإتبامل & الالالة & الإرتباطل & الدلالة & الإرتباط & الدلالة & الإرتباط & الدلالة & الإرتباط & المعلغت \\
\hline$* * \cdot, \cdot 1$ & $\cdot, \varepsilon$ & $\cdot, r)$ & $\cdot, 00$ & $* *, \cdot, 1$ & $\cdot, I V$ & $\cdot, 01$ & •, IV & $\cdot, .9$ & $\cdot, 0 \leqslant r$ & $\cdot, 07$ & •, $\leqslant Y$ & الألثناءوثة \\
\hline$\cdot, 0 \leqslant$ & $\vee . \varepsilon$ & $* *, \cdot, 1$ & $r$ r., & •, Or & $r \leq, 1$ & $* *, \cdot, 1$ & $r+$, & •, Ir & $r q, \wedge q$ & $* * \cdot, \cdot 1$ & $r q, Y$ & الجنسية \\
\hline$* * \cdot, \cdot 1$ & q.V & $\cdot, \times)$ & $\vee \wedge, \Lambda$ & $* *, \cdot, 1$ & $r T, Y$ & $\cdot, \times)$ & $T Y, \varepsilon$ & $* * \cdot, \cdot 1$ & Or,OA & $\cdot, 01$ & 07,7 & الزبكراج \\
\hline$\cdot, \leq 9$ & 1,1 & •, Or & $T \leq, r$ & - ro & $r \uparrow, \Lambda$ & C & $\uparrow \wedge, \uparrow$ & •, 9 \& & $T V, r Y$ & $\cdot, \leqslant 9$ & $V r, \varepsilon$ & العنلاقية \\
\hline$\cdot, 17$ & $r r, q$ & ד & $r, 1$ & $\cdot, 90$ & $\Gamma, \Lambda$ & $* *,,+4$ & 1,09 & דצ & $Y, Y \cdot Y$ & $\cdot, 7$ & $v, r$. & الأطفال \\
\hline -, \& & $1, \varepsilon$ & $\cdot, 79$ & $\curlyvee, \varepsilon$ & . Or & $r, r$ & $* *, \cdot \wedge$ & $r, r r$ & $\cdot, V_{1}$ & •, 9 \& & זי, • & •, Kr & المبحوثية \\
\hline$* * \cdot, \cdot 1$ & $\Lambda 1, r$ & $\cdot, 71$ & $9 Y, \varepsilon$ & $* * \cdot, \cdot 1$ & $r \cdot, l$ & $\cdot, V \pi$ & 94,1 & $* \cdot, \cdot 0$ & $v 1,19$ & $\cdot, .9$ & $\mathrm{~V} 7,9$ & الإنجار \\
\hline , & 1,7 & ****, & $\cdot, 9$ & •, IT & $1, \varepsilon$ & $\cdot, Y V$ & $1, r$ & $\cdot, \cdot 7$ & $1,0 \mathrm{~V}$ & $\cdot, \cdot r$ & $r, r \varepsilon$ & الإنتجري \\
\hline •, & $00, r$ & $* * \cdot, \cdot, 1$ & $\wedge v, \mathrm{~V}$ & $\cdot, r V$ & $\varepsilon \varepsilon, Y$ & $* * *, \cdot 1$ & $17, \varepsilon$ & •, YY & $r \cdot, 9)$ & $\cdot, \cdot 1$ & • or & الإفجاي \\
\hline זT, & $1, r$ & $* \cdot, \cdot$, & 1,1 & •, $\leqslant$ T & 1,1 & $* \cdot, \cdot 1$ & $r, 0$ & D & $1, r v$ & $\cdot, \cdot r$ & $1, r 4$ & الزالزئنابير \\
\hline •, & $r, \Lambda$ & $* * \cdot, \cdot 1$ & 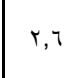 & $\cdot, 9$ & $1 \mathrm{r},$. & $* *,, \cdot 1$ & $\Gamma, \uparrow$ & $\cdot, \cdot 1$ & $1,9 \mathrm{~V}$ & $* * \cdot, \cdot, 1$ & r,or & الزنسيج \\
\hline$* \cdot, \cdot$, & 1,7 & • & $1, \mathrm{~V}$ & $\cdot$, IV & $r, \uparrow$ & $* \cdot, \cdot r$ & $1, \varepsilon$ & $\cdot, \cdot \wedge$ & $r, .9$ & - ro & 1,01 & التنظيلة الأسزة \\
\hline$* \cdot, \cdot$, & $r, \uparrow$ & • & $1, \cdot$ & $\cdot, \wedge 9$ & $\cdot, 7$ & $* *, \cdot, 1$ & $r, \uparrow$ & $\cdot, 10$ & $\cdot, 7 \Lambda$ & • & $\cdot, \wedge 4$ & أولّ فابل \\
\hline$\cdot, 7$ & $r, V$ & •, IT & $\curlyvee, \Lambda$ & $\cdot, r)$ & $\varepsilon, V$ & •, IY & $r, 0$ & $\cdot, .9$ & $\varepsilon, 1$. & •, ro & r,Tr & الالأطفين \\
\hline
\end{tabular}

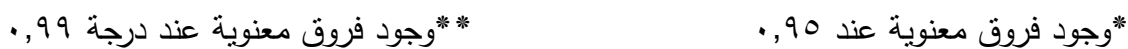

يتضح من هذا الجدول الفروق بين الحضر والربف من خلال مقياس الخصوبة وعدد من

المتغيرات الداخلة فيه.

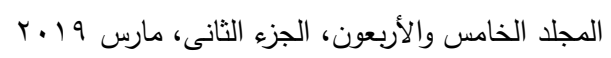




$$
\text { ويتضح من الجدول الآتي:- }
$$

• توجد فروق معنوية بين العينات في الريف والحضر على مقياس الخصوبة عند درجة معنوية 99, ، ب بين الخصوبة وسن المبحوثة أثناء فتره إجراء الدراسة، وكذلك مع الزواج المبكر للفتاة لصالح ريف الوجه البحري وريف الوجه القبلي وإجمالي الريف. توجد فروق معنوية بين الخصوبة عند درجة معنوية 99,، ،، بين العلاقة الجنسية بين الزوجين في كل من حضر الوجه البحري والوجه القبلي، ولم توجد أب فروق في الريف. توجد فروق داله معنوية بين الخصوبة وعدد الأطفال الأحياء داخل الأسرة بدرجة معنوية

$$
\text { 99, • في حضر الوجه القبلي فقط. }
$$

• توجد فروق معنوية داله بين الخصوبة ، وكون المبحوثة مختته بدرجة معنوية 99, • في حضر الوجه القبلي فقط، ولا توجد فروق داله في باقي العينات. • توجد فروق معنوية دالة بين الخصوبة واتخاذ قرار الإنجاب بالأسرة عند درجة معنوية

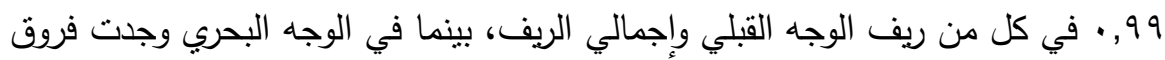

$$
\text { دالة معنوية عند } 90 \text {, • في ريف وجن ريف بحري. }
$$

توجد فروق دالة معنوية بين الخصوبة والإنجاب المتكرر للمرأة عند درجة معنوية 99 و, •

$$
\text { في حضر الوجه البحري، وإجمالي الحضر فقط. }
$$
• توجد فروق دالة معنوية عند درجة 90 , · بين الخصوبة ورغبة الزوجين في تأخير الإنجاب

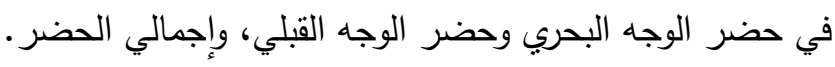
• توجد فروق دالة معنوية عند درجة 99, · ب بين الخصوبة وعنف الزوج في حضر الزبه الوجه

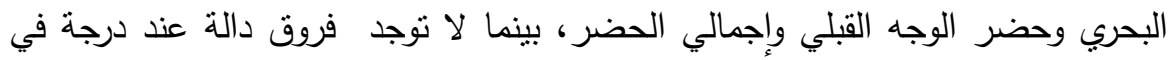

$$
\text { ريف الوجه البحري وريف الوجه القبلي، وإجمالي الريف. }
$$

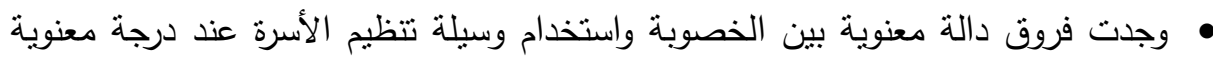

$$
\text { 90, • في حضر الوجه القبلي، إجمالي الريف عموما. }
$$
• وجدت فروق دالة عند درجة معنوية 99, • بين السن عند إنجاب أول طفل والخصوبة في حضر الوجه القبلي، وبدرجة ثقة 90\% في إجمالي الريف. 
• لا توجد فروق دالة بين الخصوبة وبين الحرية في العلاقة الجنسية، وبين عدد الأطفال

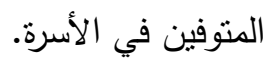

الفرض الثاني: "من المتوقع وجود فروف جوهرية دالة إحصائياً بين المرأة في الريف والحضر على مقياس الحالة الصحية".

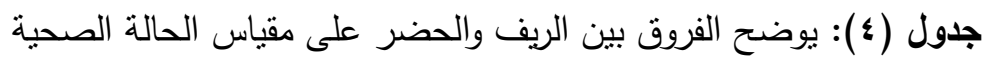

\begin{tabular}{|c|c|c|c|c|c|c|c|c|c|c|c|c|}
\hline \multicolumn{4}{|c|}{ الإجمالى } & \multicolumn{4}{|c|}{ الوجه القبلي } & \multicolumn{4}{|c|}{ الوجه البحري } & \multirow{3}{*}{ العلاقة } \\
\hline \multicolumn{2}{|c|}{ ريف } & \multicolumn{2}{|c|}{ حضر } & \multicolumn{2}{|c|}{ ريف } & \multicolumn{2}{|c|}{ حضر } & \multicolumn{2}{|c|}{ ريف } & \multicolumn{2}{|c|}{ حضر } & \\
\hline الدلالة & الارتباط & الالالة & الارتباط & الدلالة & الارتباطل & الالالة & |لارتباطل & الالالة & | الارتباط & |لادلة & الارتباط & \\
\hline$\cdot, Y_{T}$ & $\cdot, r \varepsilon$ & $\cdot, \pi r$ & $\cdot, 9 \pi$ & $\cdot, Y_{\Lambda}$ & 1,11 & $\cdot, r V$ & $1, .9$ & $\cdot, \leqslant T$ & $1, \cdot \varepsilon$ & $\cdot, \wedge 9$ & $\cdot, \wedge \mathrm{T}$ & طول المبحوثة \\
\hline$*, \cdot 1$ & . & $\cdot, \leqslant 9$ &., 99 & $*, \cdot r$ & $1, \wedge 1$ & $\cdot, 7 \leqslant$ & $\cdot, 19$ &., 0 & $\cdot, 99$ & $\cdot, T V$ & $\cdot, \wedge 9$ & حجم المبحوثة \\
\hline$*, .0$ & $\pi, \varepsilon \varepsilon$ & $\cdot, I T V$ & $\vee \neg, 0 \wedge$ & $*, \cdot \wedge$ & $r V, T r$ & $\cdot, \mathrm{V} V$ & $r q, \vee r$ & $\cdot, \cdot \leq$ & $V Y, 1 \wedge$ & $\cdot, v_{0}$ & $\vee ०, \vee \wedge$ & انتظهمرية الاورة \\
\hline$\cdot, 1 \leq$ & $\cdot, 14$ & $*,, \cdot \leq$ & דיז, & $\cdot, 00$ & $\cdot, 99$ & $\cdot, 7 \leqslant$ & $\cdot, \mathrm{VT}$ & $\cdot, r q$ & 1,17 & $* \cdot, \cdot r$ & $1,7 \mathrm{~V}$ & وجود إعاقة \\
\hline$\cdot, 91$ & $\cdot 97$ & $* *,+, 1$ & $1,9 \pi$ & $\cdot, Y_{1}$ & $1, \leqslant r$ & $* *, \ldots r$ & $1, r$ & $\cdot, 17$ & $1,0 \mathrm{~V}$ & $* *, \cdot r$ & $r, r \varepsilon$ & حدوث إجهاض \\
\hline$\cdot, r \leq$ & $\cdot, \wedge \vee$ & $\cdot, 07$ & $\cdot, 90$ & $\cdot, 11$ & $\cdot, Y T$ & $*, \cdot r$ & Y,M & $\cdot, \wedge \wedge$ & $\cdot, 71$ & $\cdot, 1 r$ & $\cdot, Y V$ & $\begin{array}{l}\text { الإصابة } \\
\text { STDS }\end{array}$ \\
\hline$\cdot, 9 \mathrm{~V}$ & $\cdot, \lambda r$ & 1,1 & $\cdot, \Sigma \mathrm{V}$ & $\cdot, 91$ & $\cdot$, Or & $\cdot, 9 \vee$ & $\cdot, 00$ & $\cdot, r$ & $r, r$ & $\cdot, 9$ & $\cdot, \varepsilon$ & التخخين \\
\hline$\cdot, 9$ & 1,7 & $\cdot, 79$ & $1, r$ & $\cdot, \varepsilon$ & $r, 17$ & $\cdot, 1$ & $Y, Y V$ & $\cdot, 11$ & $1, Y_{1}$ & $\cdot, 9 \leq$ & 1,7 & شرب الكحدوليات \\
\hline., 70 & $1 V, \leq 0$ & $*, \cdot r$ & $9 \leq, 9$ & $\cdot, \wedge)$ & 91,90 & $*,, 0$ & 91,90 & $\cdot, V Y$ & $|\wedge|, v$ & $* *,,+1$ & $\Lambda 1, r_{0}$ & فترة النفاس \\
\hline$\cdot, \varepsilon \varepsilon$ & $v, 1$ & • & $\wedge, .0$ & $\cdot, 0 \leqslant$ & 7,9 & $\cdot, 0 \leqslant$ & 7,9 & $\cdot, \leqslant 0$ & $\vee, \vee \wedge$ & $\cdot, 7 \leqslant$ & $0,9 V$ & بالأنيمبابة \\
\hline$* *,+1$ & rT, YT & $\cdot, \leqslant 7$ & $90, r_{1}$ & $* *, \cdot, 1$ & ru, & $\cdot, \wedge 9$ & $r 9,91$ & $* * *, \cdot 1$ & $7 \leq, 1 V$ & . T & $\vee \wedge, \wedge r$ & والإفرازات \\
\hline$\cdot, 19$ & $r \varepsilon, v$ & $*, \cdot+1$ & $1 \pi, 7$ &., 10 & $1, r \wedge$ & $* \cdot, \cdot r$ & 1,1 & $* \cdot, \cdot 1$ & $1,9 \mathrm{~V}$ & $\cdot, \leqslant \mathrm{V}$ & $1,+11$ & العقم \\
\hline$* \cdot, \cdot 1$ & $\varepsilon, \Gamma$ & $\cdot, 11$ & $r, \varepsilon 0$ & $\cdot, \wedge$ & $\cdot, 77$ & $* *,+, 1$ & r,1^ & $\cdot, 17$ & אזr & $\cdot, 11$ & $\cdot, Y_{1}$ & بالإصرطابة \\
\hline$\cdot, r \leq$ & $1, r \varepsilon$ & $\cdot, 9$ & $1, V T$ & $\cdot, \leqslant 0$ & 1,70 & $\cdot, \mathrm{V}$ & $1, \leqslant 7$ & $\cdot, 1$ & $1, r_{0}$ & $\cdot, Y V$ & 1,19 & بالإسهابة \\
\hline
\end{tabular}

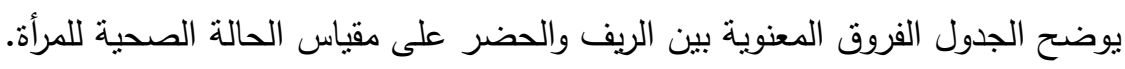




$$
\text { وقد أوضح الجدول الآتي:- }
$$

لا توجد فروق معنوية دالة خاصة بالمتغيرات الآتية: طول المبحوثة، والتدخين، وشرب

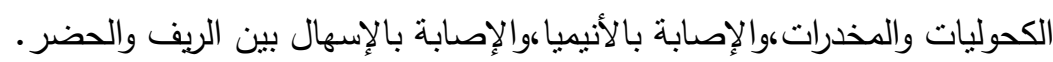

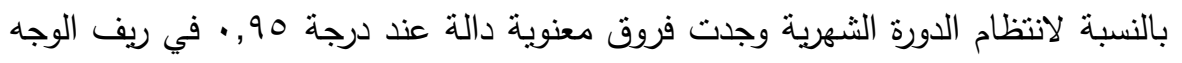
البحري وريف الوجه القبلي، وإجمالي الريف ، ولم توجد أي فروق مع أي من العينات الأخرى.

• وجدت فروق دالة معنوية عند درجة 90 , · مع وجود إعاقة جسمية لاى عينة حضر الوجه ألها

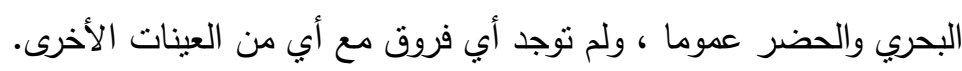
• وجدت فروق دالة معنوية عند درجة 99, • لحدوث إجهاض منكرر في حضر الونر الوجه البحري والقبلي والحضر عموما ، ولم توجد أي فروق مع أي من العند العينات الأخرى.

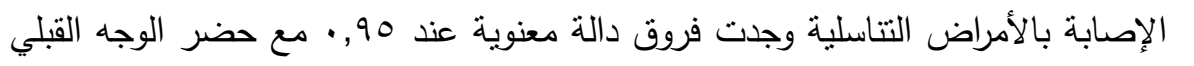
فقط، ولم توجد أب فروق مع أي من العينات الأخرى.

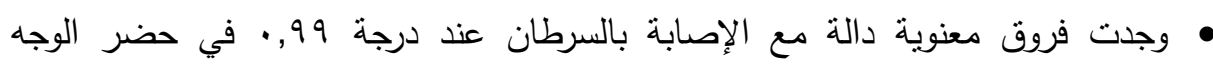

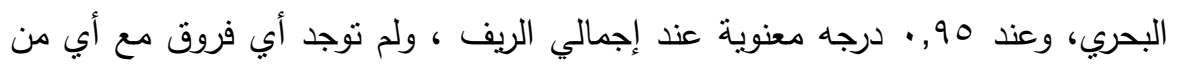

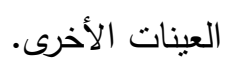

الفرض الثالث: "من المتوقع وجود علاقة جوهرية دالة إحصائياً بين خصوبة المرأة والخصائص النفسية لها في كلا من الريف والحضر ". 
مجلة العلوم البيئية

معهد الدراسات والبحوث البيئية - جامعة عين شمس لمس لئن

جدول (•): يوضح العلاقة بين الخصوبة والعوامل النفسية للمرأة

\begin{tabular}{|c|c|c|c|c|c|c|c|c|c|c|c|c|}
\hline \multicolumn{4}{|c|}{ الإجمالي } & \multicolumn{4}{|c|}{ الوجه القبلي } & \multicolumn{4}{|c|}{ الوجه البحري } & \multirow{3}{*}{ العلاقة } \\
\hline \multicolumn{2}{|c|}{ ريف } & \multicolumn{2}{|r|}{ حضر } & \multicolumn{2}{|c|}{ ريف } & \multicolumn{2}{|c|}{ حضر } & \multicolumn{2}{|c|}{ ريف } & \multicolumn{2}{|c|}{ حضر } & \\
\hline 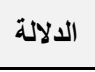 & |لارتباط & 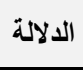 & | الارتباط & الالالة & | معامل & الدالة & | الارتباط & 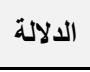 & |لارتباط & الدالة الدالة & | معامل & \\
\hline$\because, \cdot r$ & - & $*{ }_{*}^{*}, \ldots r$ & , va & $*, \cdot 1$ & | & $* \ldots, \ldots r$ & - & $*, \cdot r$ & ., & $\because, \cdot r$ & $. \times 40-$ & ضغوطة الحياة \\
\hline$\cdots, \ldots$, & -,A. & $\cdots, \ldots$, & , & $\because, .1$ & , $v \leqslant r$ & $* \ldots, \ldots$ & $0,9.1$ & $* \ldots, \ldots$ & •, А० & $* \ldots, \ldots$ & , Arr & الانفعية \\
\hline$" ., . \&$ & $\cdot, 4.1$ & , rrv & , $r V Y$ & $* \ldots, \ldots \wedge$ & ויו,י & , IrA & זיזי, & . & 年, & . Irs & , rir & اللانفوكي \\
\hline ., vv & . rraq & $\cdot ., .1$ & . 799 & צוי,. &., 111 & $* *, \ldots r$ & . $\mathrm{\vee} 9 \mathrm{~A}$ & 更, & . & $\because, .0$ & . ҮA1 & الإنبساطية \\
\hline$*, . .0$ &.,$\because 11-$ & ., \&1 & - & $" ., .0$ & - & . & - ora- & ${ }^{* ., .}$, & .,VYr- & , r,r & 证, & الانطوائية \\
\hline$*, \ldots 1$ & -,911 & $* \ldots, \ldots$ & 促, & $* *, \ldots 1$ & •,VYT & $* *, \ldots 1$ & -,A A & $*,, \&$ & . & $*, \cdot \cdot$ & •,VAr & الثخصية تقدية \\
\hline$* \ldots, \ldots$ & , Arv & $*{ }_{*}^{*}, \ldots$ & .,9rr- & $" *,, \ldots 1$ & , $9 \leqslant 0-$ & $* *, \ldots 1$ & •,^৭४- & $*, \cdot$, & -,$v \mu v$ & $* \ldots, \ldots 1$ & -, Arq- & المزاجية \\
\hline$* \ldots, \ldots 1$ &,$- 911-$ & $\cdots, \ldots$, & $\cdot, 991-$ & $\cdots, \ldots$, & , $9 \times 4-$ & $\cdots, \ldots$, & $\cdot, 9 \wedge \mathrm{V}-$ & $* *, \ldots$ &., $9 \times 1-$ & ${ }_{*}^{*}, \ldots$, & $\cdot, 901-$ & أعتراضية \\
\hline 1, & . & , rr. & . & . & , , l.r & $\therefore, .9$ & -,ril & , 10 \& & $\cdot, \mathrm{rV}$ & 促 & ., $|v|$ & قوهرية \\
\hline$*,,$. & , & 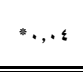 & - VIY & ., vV & - & $\bullet, .$, & 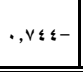 & $\cdot, \varepsilon, r$ & - $190-$ & $\cdot, ., 0$ & ,,$v \leqslant r-$ & عرض القلق \\
\hline
\end{tabular}

" وجود فروق معنوية عند 90 , • "** وجود فروق معنوية عند درجة 99 , .

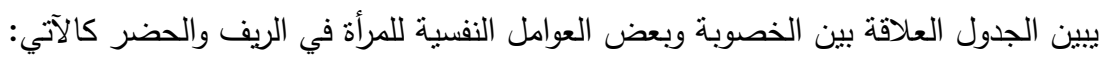
• بالنسبة لضغوط الحباة، فقد وجد ارتباط دال عكسي معنويا عند 99, · بين الخصوبة

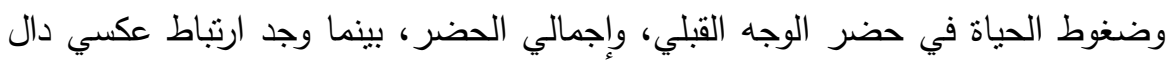
معنويا عند 90, • فى حضر وريف الوجه البحري، وريف الوجه القبلي، وإجمالي الريف.

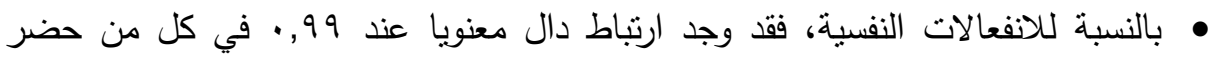
وريف الوجه البحري ، بينما وجد ارتباط دال معنويا عند 90 , ، في ريف الوجه القبلي.

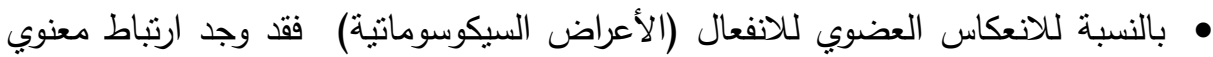

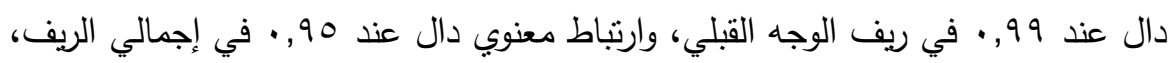
بينما لا يوجد أي ارتباط مع أي عينة أخري. 
بالنسبة للانبساطية، فقد وجد ارتباط معنوي دال عند 99, · في حضر الوجه القبلي، بينما وجد ارتباط معنوي دال عند 90, · في حضر الوجه البحري وإجمالي الحضر، ولا يوجد أي ارتباط دال في الريف.

الإنطوائية وجد ارتباط عكسي دال عند 90 , • في ريف الوجه البحري وريف الوجه القبلي

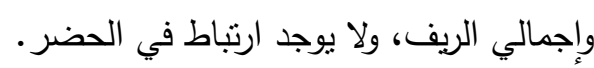

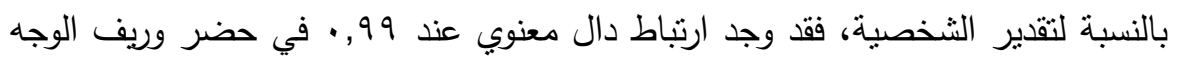

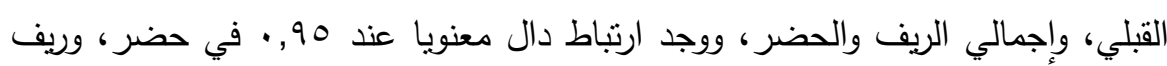
الوجه البحري. • بالنسبة للحالة المزاجية، وجد ارتباط عكسي دال معنويا عند 99,، مع حضر الوجه

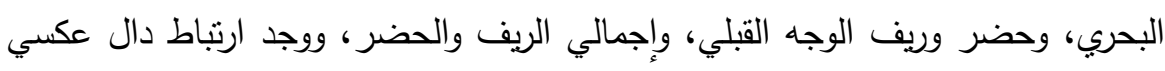

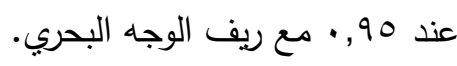
• بالنسبة للأعراض الاكتئابية، فقد وجد ارتباط عكسي دال معنويا عند 99, . في كل العينات. • ل الوجد أي ارتباط بين الخصوبة والوساوس القهرية في أي عينة.

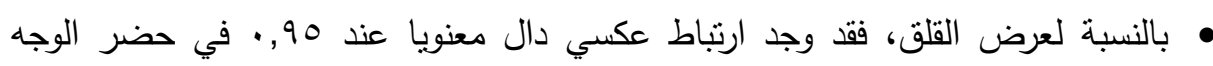

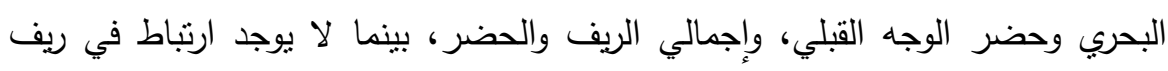
الوجه البحري، وريف الوجه القبلي. الفرض الرابع: "من المتوقع وجود علاقة جوهرية دالة إحصائياً بين خصوبة المرأة ونوعية

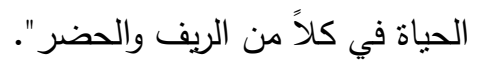


مجلة العلوم البيئية

معهد الدراسات والبحوث البيئية - جامعة عين شمس له

جدول (†): يوضح العلاقة بين الخصوبة ونوعية الحياة

\begin{tabular}{|c|c|c|c|c|c|c|c|c|c|c|c|c|}
\hline \multicolumn{4}{|c|}{ الإجمالي } & \multicolumn{4}{|c|}{ الوجه القبلي } & \multicolumn{4}{|c|}{ الوجه البحري } & \multirow{2}{*}{ العلاقة } \\
\hline \multicolumn{2}{|c|}{ ريف } & \multicolumn{2}{|c|}{ حضر } & \multicolumn{2}{|c|}{ ريف } & \multicolumn{2}{|c|}{ حضر } & \multicolumn{2}{|c|}{ ريف } & \multicolumn{2}{|c|}{ حضر } & \\
\hline الدلالة & |الارتباط & الدلادة & |لارتباط & الدلالة & معامل & الدلادة & |لارتباط & الدلالة & | الارتباط & الدلالة & |الارتباط & \\
\hline$* \cdot, \cdot 1$ & $\cdot$, РА५ & $* *, ., 1$ & $\cdot, 9 \cdot 1$ & $* \cdot, \cdot \leq$ & $\cdot, 711$ & $* *, \cdot, 1$ & $\cdot$, , AOr & $* \cdot, \cdot 1$ & $\cdot, \mathrm{VAl}$ & $* * \cdot, \cdot 1$ & $\cdot, \wedge 10$ & |الاجتماعية \\
\hline$* \cdot, \cdot 1$ & •,9Y4 & $* \cdot, \cdot 1$ & $\cdot, V Y Y$ & $* * \cdot, \cdot r$ & $\cdot, \wedge 91$ & $* \cdot, \cdot 1$ & אירוי & $* \cdot, \cdot 1$ & $\cdot$, ATV & $* \cdot, \cdot r$ & 位, & |لاقتصادية \\
\hline$* *, \cdot, 1$ & $\cdot, 9 \cdot 1$ & $* * \cdot, \cdot$, & $\cdot, \lambda \vee \neg$ & $* * \cdot, \cdot r$ & $\cdot, V \vee 1$ & $* \cdot, \cdot 1$ & • & $* * \cdot, \cdot r$ & $\cdot, \mathrm{VYI}$ & $* * \cdot, \cdot r$ & $\cdot, \wedge r \varepsilon$ & القياتية \\
\hline
\end{tabular}

* وجود فروق معنوية عند 90 , . **" وجود فروق معنوية عند درجة 99 , .

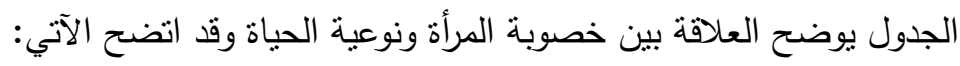

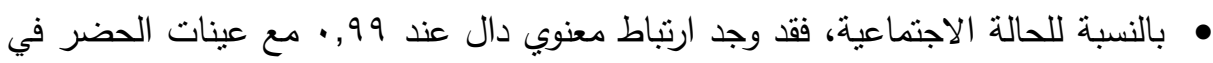
الوجه البحري والقبلي وإجمالي الحضر، ووجد ارتباط معنوي دال عند 90 ، • مع عينات الريف في وجه بحري وقبلي وإجمالي الريف. • بالنسبة للقدرات الحياتية، وجد ارتباط معنويا عند 99 , • في كل العينات، ما عدا لرئي حضر وجه بحري فقط وجد ارتباط دال معنوي عند 90 , •.

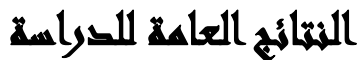

• أكدت نتائج الدراسة على وجود علاقة جوهرية دالة إحصائياً عند مستوى معنوي (0., •) بين خصوبة المرأة وبعض المتغيرات الدالة عليها في كل من الريف والحضر .

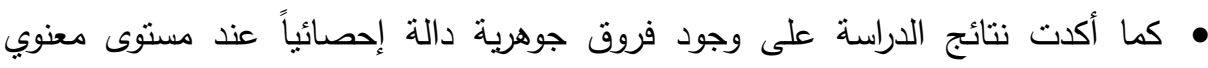
(0., • • بين المرأة في الريف والحضر على مقياس الحالة الصحية.

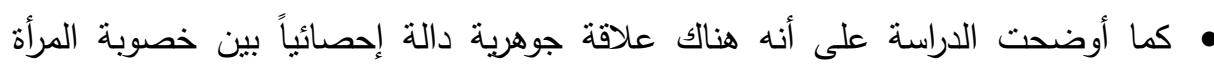
والخصائص النفسية لها عند مستوى معنوي (0. . •) في كلا من الريف والحضر . 
• وأكدت نتائج الدراسة على وجود علاقة جوهرية دالة إحصائياً بين خصوبة المرأة ونوعية

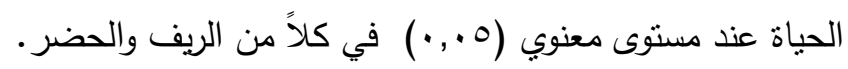

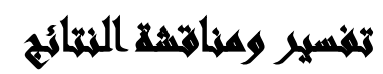

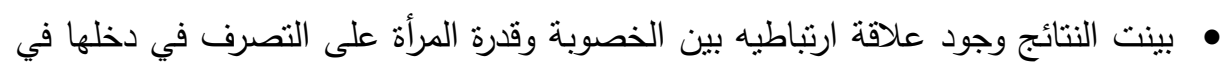
كل مجموعات الدراسة ماعدا في ريف الوجه البحري، وربما برجع ذلك إلى قلة الدخل وعدم تأثيره في ميزانية البيت.

• وتتفق هذه الدراسة مع كثير من الدراسات كدراسة (فريال عبد القادر، شفيق حسن، "Walker\&Jennifer قرارها الإنجابي، ويرجع ذلك للإسنقلالية الاقتصادية للمرأة.

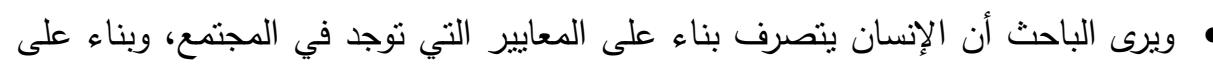

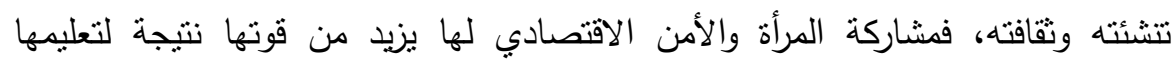
وتثافتها. • كما أثنارت النتائج المستخلصة من الدراسة، وجود فروق دالة معنوية بين الريف والحضر في صالح الريف نحو أهمية التعليم.

• وقد اتفقت نتائج الدراسة مع دراسة " هويدا محمد، فريال عبدالقادر" حيث أكدت على وجود

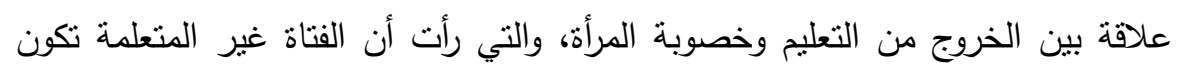

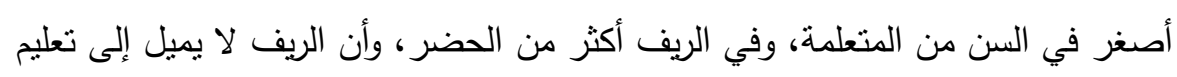
الفتاة إما للفقر أو لأنها عادة. ويرى الباحث أن حضر الوجه القبلي لازال أقل انفتاحاً علالتعليم بعكس الوجه البحري هذا أناء

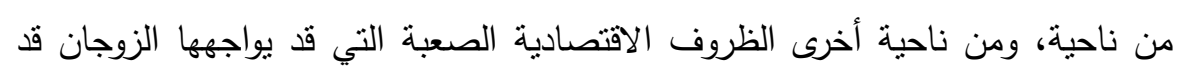
تؤثر على الطلب على التعليم. وأشارت النتائج إلى وجود علاقة ارتباطية بين خصوبة المرأة والعمل في كل العينات ماعدا ريف الوجه القبلي. 
• وقد اتسقت هذه النتائج مع دراسة "ناهد صالح، عثمان محمد" حول رغبة المرأة في الإنجاب تزداد بزيادة المستوى الاقتصادي، وكذلك بقصد فترة المباعدة بين الولادات، كما أوضحت نأثير المهنة على تفضيلات الإنجاب، وحجم الأسرة.

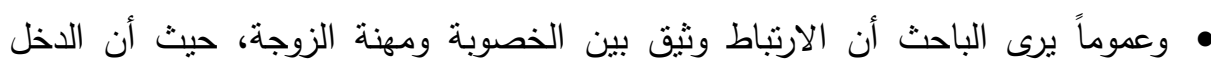
يعطيها قوة في فرض رأيها حول هذا السلوك وطريقة إنجاب الأطفال.

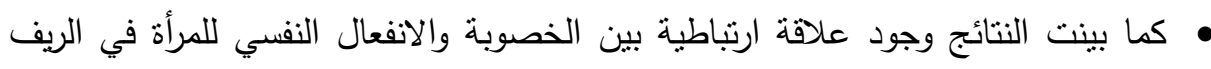
والحضر.

• ويرى الباحث أن الانفعال ما يكون في بعض الأحيان دافع ذو قوة، تدفع الإنسان إلى في

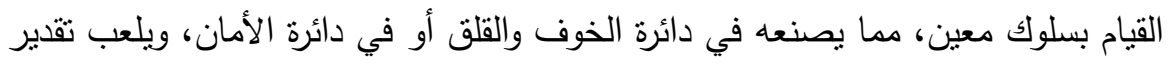

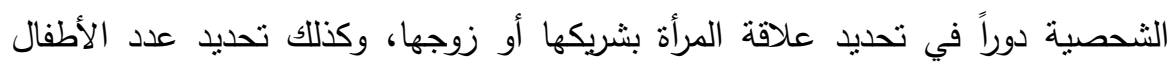

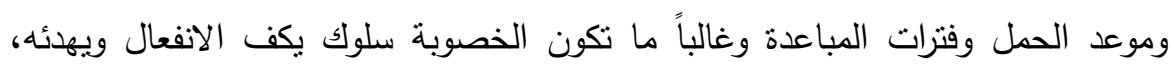
وتلعب العواطف والمشاعر دوراً كبيراً فيه. • كما بينت النتائج وجود ارتباط دال عكسى بين سن المبحوث والخصوبة لها في كل وله العينات سواء في الريف والحضر . • اتسقت تلك النتائج مع دراسة "نجاة محمود، فريال عبدالقادر" حول تأثير السن في زواج الفتاة، فى وجود علاقة ارتباطية بين سن الزوجة وفرص زواجها وخصوبتها وعدد الأبناء لكل سيدة.

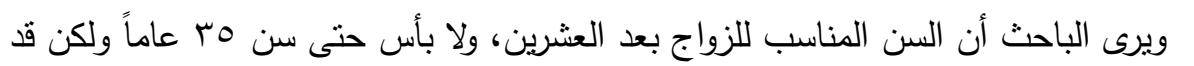

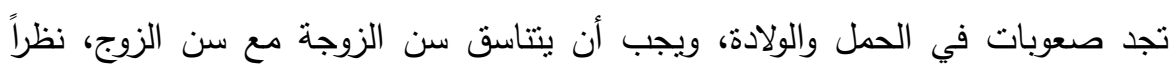

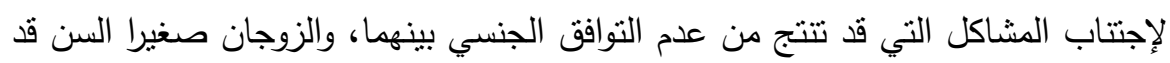
ينتج عنهما وبينهما خلافات لعدم النضج العقلي والعاطفي بينهما. 


\section{تموسيايت الصوراهة}

• أهية تهيئة المناخ والظروف المناسبة سواء النفسية والبيئية والصحية للمرأة لكي ينعكس

ذلك على حياتها وخصوبتها.

• أجراء العديد من الدراسات المختلفة التي تهتم بدراسة العوامل المؤثرة على الخصوبة للمرأة. • إدخال مفاهيم صحة المرأة بشكل أساسي في مقررات التعليم من حيث تأثيرات البيئة

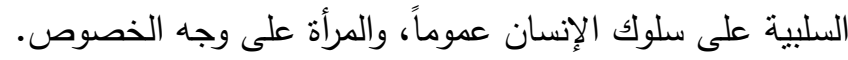

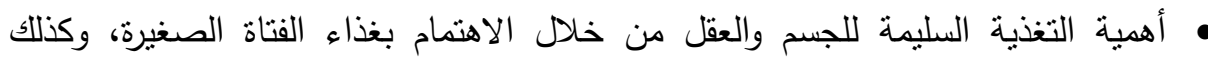

الاهتمام بالنواحي العقلية والإبداعية والابتكارية لديها.

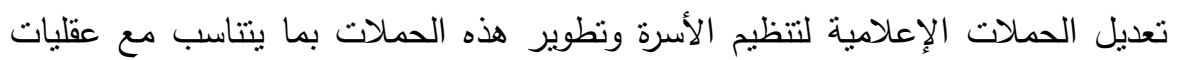

المجتمع وما يتتاسب مع ثقافة المرأة في مصر .

\section{مرايج الدوالهة}

أحمد زكي بدوى (9AvV): معجم مصطلحات الرعاية والتتمية الاجتماعية، دار الكتاب

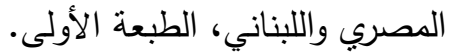

المجلس القومي للمرأة ( ( . ب): المرأة المصرية والخطة القومية، المؤتمر الثاني- مارس،

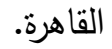

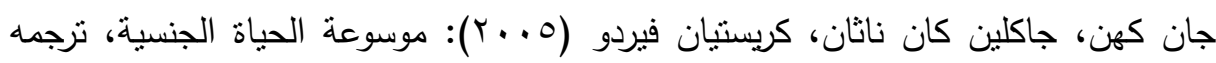
محمد حسين شمس الدين، دار الفراشة، بيروت كان لبنان لبنان.

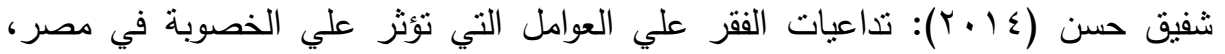

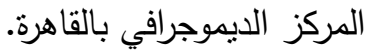

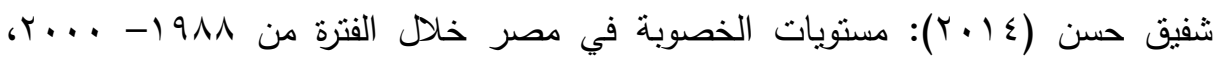
المركز الديموجرافي بالقاهرة.

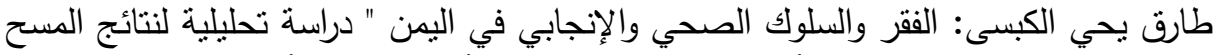
اليمني لصحة الأسرة "، المؤتمر العربي الأول لصحة الأسرة والسكان، الجامعة الصنة

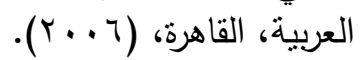


طلعت مصطفى السروجى: ثلاثية التخطيط ورأس المال الاجتماعى والتحديث إستراتيجية

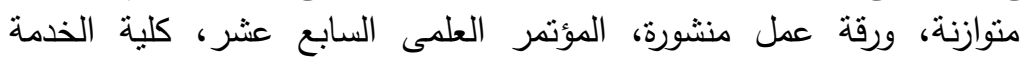
الاجتماعية، جامعة حلوان، (Y... (Y).

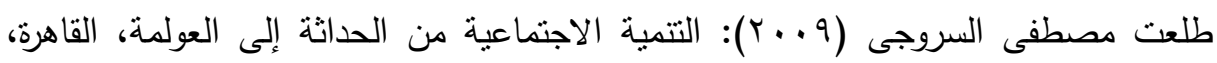

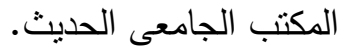

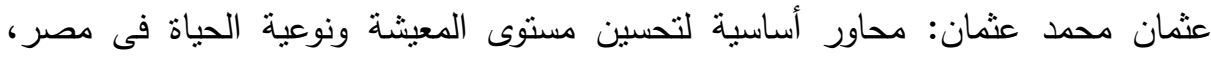

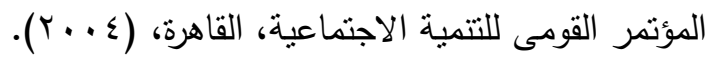

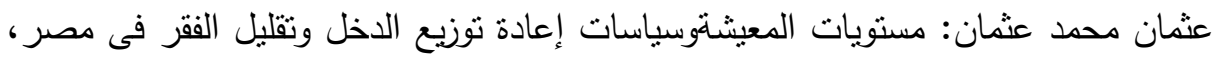

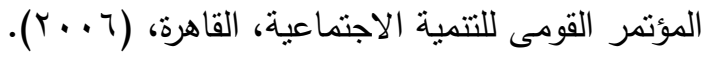

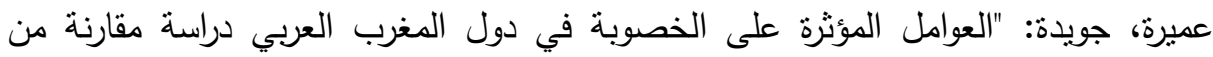

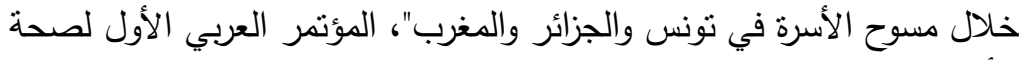

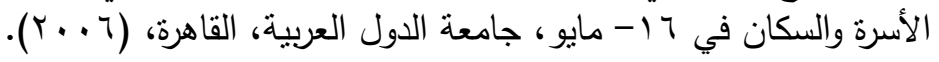

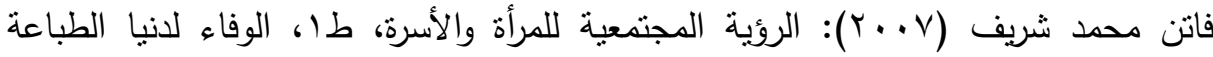
والنشر، الإسكندرية.

فربال عبدالقادر: العوامل المباشرة والغير مباشرة المؤثرة علي الخصوبة واتجاهاتها، الجهاز

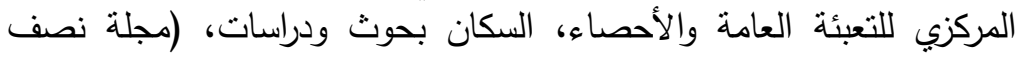

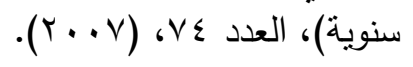

فريال عبد القادر : تأثير السن عند الزواج الأول علي الخصوبة، الجهاز المركزي للتعبئة العامة

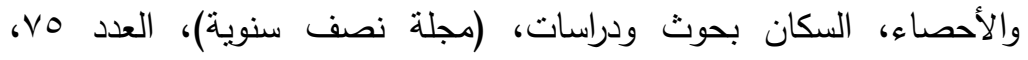

$$
\cdot(r \cdot v)
$$

محمد عبد الرحمن الشرنوبي (^ . . ץ): جغرافية السكان، مكتبة الأنجلو المصرية، القاهرة.

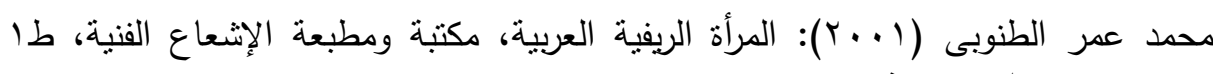
الإسكندرية.

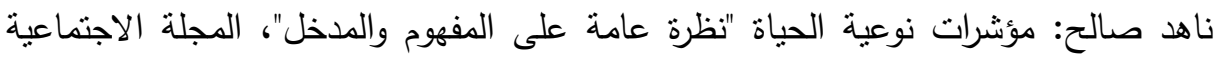

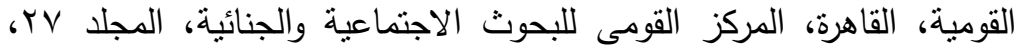

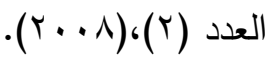

$$
\text { المجلد الخامس والأربعون، الجزء الثانى، مارس } 19 \text { بـ }
$$


هويدا محمد عبد المنعم: محو أمية المرأة وتحسين نوعية الحياة كمطلب لتحقيق التتمية

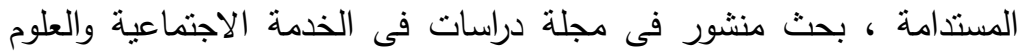

الإنسانية، كلية الخدمة الاجتماعية، جامعة حلوان، الجزء الثالث، (1 . . ب).

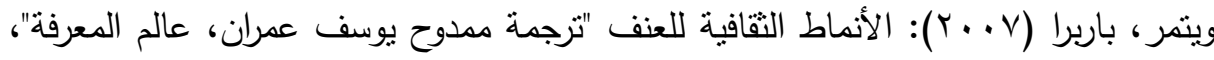

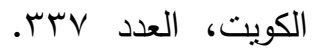

Balthazart, Jacques \& Tlemcani,Omar \& Ball, Gregory F. (2004): Do Sex differences in the brain explain sex differences in hormonal induction of reproductive behavior, school for Neurosciences, Lab. of Biochemistry, Belguim.

Climere, Dan Oriji (2004): Determinants of racial fertility differentials in some urban area of South Africa, University of Wit Watersrand , Dept. of Sociology. Johannesburg, South Africa.

Cohen. S. A. (1980): After effects of Stress on human Performance and Social behavior, a review of Research and Theory, Psychological, Bulletin,1980.

Omideyi, Adekumbi Kehinde (2004): Female autonomy, socioeconomic and reproductive behavior in sub-saharian Africa, international journal of psychological, vol (5), part (1).

Seema Dedhiya (2003): The Concept and measures of quality of life, Chicago, USA.

Walker \& Jennifer: Rural Women Needs, American Mental health, Counselor association journal, Vol. 24, (2002)

Walker \& Melinda (2008): Supportive Care of Rural Women, Psycho. Oncology, Vol. 17(1), United Kingdom. 
مجلة العلوم البيئية

معهد الدراسات والبحوث البيئية - جامعة عين شمس لمس لئن

\title{
LIFE QUALITY AND ITS RELATIONSHIP WITH FERTILITY OF EGYPTIAN WOMEN IN THE VIEW OF PSYCHOLOGICAL FACTORS FIELD STUDY ON DIFFERENT SOCIAL PLACES
}

Hussein A. Hussein ${ }^{(1)}$; Mustafa I. Awad ${ }^{(1)}$; Mustafa H. Ragab ${ }^{(1)}$; Ferial A. Abdelkader ${ }^{(2)}$ and Ahmed A. Ahmed ${ }^{(3)}$

1) Institute of Environmental Studies and Research, Ain Shams University 2) Demographic Center in Cairo 3) Director of the Arab Project for Family Health, League of Arab States.

\begin{abstract}
The purpose of this study is to determine the relationship between female fertility and certain variables in rural and urban areas. The aim of this study is to determine the differences between rural and urban on the health status of women. This study belongs to the pattern of descriptive studies in order to measure the relationship between two variables, A dependent variable is the fertility of women in the light of some psychological factors. The present study is based on the following methods: a quality of life measure by the researcher, a measure of psychological factors affecting the fertility of women by the researcher. The sample of the study was in a simple random sample. The sample size was in the Upper Upper Egypt (128) and the Upper Egypt (152). A simple random sample (119) was selected in rural Upper Egypt and a simple random sample was (138) single in Upper Upper Egypt.

The results of the study confirmed that there was a statistically significant relationship at a significant level $(0.05)$ between fertility The main recommendations of the study were to introduce the concepts of women's health mainly in education decisions in terms of the negative effects of the environment on human behavior in general, and women in particular.
\end{abstract}

$$
\text { المجلد الخامس والأربعون، الجزء الثانى، مارس } 19
$$

